\title{
Enhancement of Excitatory Synaptic Integration by GABAergic Inhibition in the Subthalamic Nucleus
}

\author{
Jérôme Baufreton, Jeremy F. Atherton, D. James Surmeier, and Mark D. Bevan \\ Department of Physiology, Feinberg School of Medicine, Northwestern University, Chicago, Illinois 60611
}

The activity patterns of subthalamic nucleus (STN) neurons, which are intimately related to normal movement and abnormal movement in Parkinson's disease (PD), are sculpted by feedback GABAergic inhibition from the reciprocally connected globus pallidus (GP). To understand the principles underlying the integration of GABAergic inputs, we used gramicidin-based patch-clamp recording of STN neurons in rat brain slices. Voltage-dependent $\mathrm{Na}^{+}\left(\mathrm{Na}_{\mathrm{v}}\right)$ channels actively truncated synthetic IPSPs and were required for autonomous activity. In contrast, hyperpolarization-activated cyclic nucleotide-gated and class 3 voltage-dependent $\mathrm{Ca}^{2+}$ channels contributed minimally to the integration of single or low-frequency trains of IPSPs and autonomous activity. Interestingly, IPSPs modified action potentials (APs) in a manner that suggested IPSPs enhanced postsynaptic $\mathrm{Na}_{\mathrm{v}}$ channel availability. This possibility was confirmed in acutely isolated STN neurons using current-clamp recordings containing IPSPs as voltage-clamp waveforms. Tetrodotoxin-sensitive subthreshold and spike-associated $\mathrm{Na}^{+}$currents declined during autonomous spiking but were indeed transiently boosted after IPSPs. A functional consequence of inhibition-dependent augmentation of postsynaptic excitability was that EPSP-AP coupling was dramatically improved when IPSPs preceded EPSPs.

Because STN neuronal activity exhibits coherence with cortical $\beta$-oscillations in PD, we tested how rhythmic sequences of cortical EPSPs were integrated in the absence and presence of feedback inhibition. STN neuronal activity was consistently entrained by EPSPs only in the presence of feedback inhibition. These observations suggest that feedback inhibition from the GP is critical for the emergence of coherent $\beta$-oscillations between the cortex and STN in PD.

Key words: basal ganglia; inactivation; IPSP; Parkinson's disease; sodium channel; synchronization

\section{Introduction}

The subthalamic nucleus (STN) is a key integrative structure of the basal ganglia, which receives a GABAergic input from the reciprocally connected globus pallidus (GP) and a glutamatergic input from the cortex (Smith et al., 1998). Because STN activity is correlated with normal movement (Wichmann et al., 1994) and disordered movement in idiopathic/experimental models of Parkinson's disease (PD) (Bergman et al., 1994; Levy et al., 2002), intrinsic and synaptic mechanisms that pattern the discharge of STN neurons are of interest.

In vitro and in the absence of synaptic input, STN neurons exhibit autonomous rhythmic single-spike activity that is generated by voltage-dependent $\mathrm{Na}^{+}\left(\mathrm{Na}_{\mathrm{v}}\right)$ channels, despite the fact that $40-50 \%$ of $\mathrm{Na}_{\mathrm{v}}$ channels are inactivated (Bevan and Wilson, 1999; Beurrier at al., 2000; Do and Bean, 2003). In addition to $\mathrm{Na}_{\mathrm{v}}$ channels, other potential contributors to activity and synaptic integration are hyperpolarization-activated cyclic nucleotidegated $(\mathrm{HCN})$ and class 3 voltage-dependent $\mathrm{Ca}^{2+}\left(\mathrm{Ca}_{\mathrm{v}} 3\right)$ chan-

Received March 24, 2005; revised July 29, 2005; accepted July 29, 2005.

This research was supported by National Institutes of Health-National Institute for Neurological Disorders and Stroke Grants NS041280 (M.D.B.) and NS047085 (M.D.B., D.J.S). We thank Peter Magill, Marco Martina, and Charlie Wilson for constructive comments. This study is dedicated to Eberhard Buhl.

Correspondence should be addressed to Mark D. Bevan, Department of Physiology, Feinberg School of Medicine, Northwestern University, 303 East Chicago Avenue, Chicago, IL 60611. E-mail: m-bevan@northwestern.edu. DOI:10.1523/JNEUROSCI.1163-05.2005

Copyright $\odot 2005$ Society for Neuroscience $\quad$ 0270-6474/05/258505-13\$15.00/0 nels (Huguenard, 1996; Williams and Stuart, 2003; Chan et al., 2004), which underlie prominent inward currents in STN neurons (Beurrier et al., 2000; Song et al., 2000).

Single/low-frequency stimulation of putative GP fibers elicits $\mathrm{GABA}_{\mathrm{A}}$ receptor-mediated IPSPs in STN neurons that produce a pause and reset the phase of autonomous oscillation (Bevan et al., 2002a). As such, the first goal of this study was to determine how these patterns of inhibition engage intrinsic conductances mediated by $\mathrm{Na}_{\mathrm{v}}, \mathrm{HCN}$, and $\mathrm{Ca}_{\mathrm{v}} 3$ channels in STN neurons. It was observed that $\mathrm{Na}_{\mathrm{v}}$ rather than $\mathrm{HCN}$ or $\mathrm{Ca}_{\mathrm{v}} 3$ channels were critical for the integration of single or low-frequency IPSPs and were deactivated and then deinactivated by synaptic inhibition.

An efficient input sequence for the precise timing of action potentials (APs) is a brief hyperpolarization, followed by a depolarizing event (Mainen and Sejnowski, 1995). Because hyperpolarizing events were proposed to increase firing probability by reducing $\mathrm{Na}_{\mathrm{v}}$ channel inactivation in the postsynaptic neuron, our second objective was to test whether GABAergic IPSPs could also modify the integrative properties of STN neurons and enhance the efficacy with which subsequent excitatory inputs generate APs.

Abnormal synchronized oscillatory activity in the STN and its target structures is an emergent property of PD (Bevan et al., 2002b; Brown, 2003; Dostrovsky and Bergman, 2004). Lowfrequency $(<10 \mathrm{~Hz})$ rhythmic activity may be generated within the STN-GP network (Plenz and Kitai, 1999) through a mecha- 
nism similar to that underlying thalamic spindle activity (McCormick and Bal, 1997). However, coherent cortical and STN activity in the $\beta$-frequency range ( $13-30 \mathrm{~Hz}$ ) has been more commonly observed and the phase relationships of potentials in the cortex and basal ganglia suggest that the cortex drives pathological STN activity (Brown, 2003; Dostrovsky and Bergman, 2004). Because the loss of dopamine in the STN in PD may amplify feedback inhibition from the GP (Shen and Johnson, 2000, 2005; Cragg et al., 2004), the final objective was to determine whether feedback inhibition, through an enhancement of postsynaptic excitability, could facilitate the entrainment of APs in STN neurons by rhythmic, cortical input.

\section{Materials and Methods}

\section{Slice preparation and electrophysiology}

Electrophysiological recordings were performed using brain slices prepared from 110 16- to 25-d-old Sprague Dawley rats (Charles River Laboratories, Wilmington, MA). Animals were anesthetized with a mixture of ketamine and xylazine and perfused transcardially with ice-cold modified artificial CSF (ACSF) that was equilibrated with $95 \% \mathrm{O}_{2}$ and $5 \%$ $\mathrm{CO}_{2}$ and contained the following (in mM): 230 sucrose, $26 \mathrm{NaHCO}_{3}, 2.5$ $\mathrm{KCl}, 1.25 \mathrm{Na}_{2} \mathrm{HPO}_{4}, 0.5 \mathrm{CaCl}_{2}, 10 \mathrm{MgSO}_{4}$, and 10 glucose. The brain was then quickly removed from the skull, blocked in the sagittal plane, glued to the stage of a vibratome (3000 Deluxe; Technical Products International, St. Louis, MO), and submerged in ice-cold modified ACSF. Slices, $300 \mu \mathrm{m}$ thick, containing the STN were cut and transferred to a holding chamber at room temperature in ACSF that was equilibrated with $95 \%$ $\mathrm{O}_{2}$ and $5 \% \mathrm{CO}_{2}$ and contained the following (in $\mathrm{mm}$ ): $126 \mathrm{NaCl}, 26$ $\mathrm{NaHCO}_{3}, 2.5 \mathrm{KCl}, 1.25 \mathrm{Na}_{2} \mathrm{HPO}_{4}, 2 \mathrm{CaCl}_{2}, 2 \mathrm{MgSO}_{4}$, and 10 glucose.

\section{Perforated patch current-clamp recording}

Single slices were then transferred to a recording chamber and perfused continuously with oxygenated $\mathrm{ACSF}$ at $37^{\circ} \mathrm{C}$, in which they were visualized using infrared gradient contrast video microscopy (Dodt et al., 1999) (Infrapatch workstation; Luigs \& Neumann, Ratingen, Germany) and a $40 \times$ water-immersion objective (Axioskop; Zeiss, Oberkochen, Germany). Somatic recordings were made using patch pipettes prepared from standard-wall borosilicate glass capillaries (G150-4; Warner Instruments, Hamden, CT) with a micropipette puller (P-97; Sutter Instruments, Novato, CA) and were front-filled with the following (in mM): 110 $\mathrm{K}-\mathrm{MeSO}_{4}, 25 \mathrm{KCl}, 3.6 \mathrm{NaCl}, 1 \mathrm{MgCl}_{2} \cdot 6 \mathrm{H}_{2} \mathrm{O}, 10 \mathrm{HEPES}, 0.1 \mathrm{Na}_{4}$ EGTA, $0.4 \mathrm{Na}_{3} \mathrm{GTP}$, and $2 \mathrm{Mg}_{1.5} \mathrm{ATP}$. The $\mathrm{pH}$ and osmolarity of the pipette solution were 7.3 and $290 \mathrm{mOsm}$, respectively. Patch pipettes were then backfilled with the same pipette solution containing gramicidin at a concentration of $\sim 15 \mu \mathrm{g} / \mathrm{ml}$. Gramicidin was used as the pore-forming agent for perforated patch recordings because gramicidin channels are permeable solely to monovalent cations and small neutral molecules. This approach therefore enables the intrinsic physiological properties of STN neurons and the natural gradient of anions that permeate $\mathrm{GABA}_{\mathrm{A}}$ receptors to be preserved (Kyrozis and Reichling, 1995; Bevan et al., 2000, 2002a). Deliberate or accidental establishment of the whole-cell configuration was recognized as a sudden drop in series resistance, a depolarizing shift in the equilibrium potential of the evoked $\mathrm{GABA}_{\mathrm{A}}$ receptormediated IPSP, and an $\sim 5 \mathrm{mV}$ offset in membrane potential. The value of the offset was smaller than the experimentally measured, and the empirically calculated, junction potential between the electrode solution and the external media of $9 \mathrm{mV}$ (Neher, 1992; Barry, 1994). The recorded membrane potential was therefore $\sim 4 \mathrm{mV}$ more depolarized than the true membrane potential and was corrected accordingly off-line. Data were recorded using an Axopatch 200B or a Multiclamp 700B amplifier controlled by Axograph 4.0 and Clampex 9.0 (Molecular Devices, Union City, CA), respectively. Signals were digitized at $50 \mathrm{kHz}$ and low-pass filtered at $10 \mathrm{kHz}$. In some illustrations of these data, APs have been truncated at $0 \mathrm{mV}$.

Synaptic stimulation. GABAergic and glutamatergic postsynaptic potentials were elicited with bipolar stimulation (A360 stimulus isolator; World Precision Instruments, Sarasota, FL) of the internal capsule rostral to the STN. The poles of stimulation were selected from a custom-built matrix of 20 stimulation electrodes (Cragg et al., 2004) (MX54CBWMB1; Frederick Haer Company, Bowdoinham, ME). The two electrodes selected for stimulation were those that generated the largest GABAergic or glutamatergic synaptic potentials in the absence of antidromic activation. Supramaximal stimulation (intensity, $0.1-0.9 \mathrm{~mA}$; duration, $0.1 \mathrm{~ms}$ ) was used so that failure to stimulate fibers would contribute little to the variability of the responses.

$\mathrm{GABA}_{\mathrm{A}}$ receptor-mediated IPSPs were evoked in isolation by bath application of ACSF containing $1 \mu \mathrm{M}$ CGP55845 [(2S)-3-\{[(1S)-1-(3,4dichlorophenyl)ethyl] amino-2-hydroxypropyl)(phenylmethyl)phosphinic acid], $50 \mu \mathrm{M} \mathrm{D}-(-)$-2-amino-5-phosphonopentanoic acid (APV), 20 $\mu \mathrm{M}$ 6,7-dinitroquinoxaline-2,3-dione (DNQX) to block $\mathrm{GABA}_{\mathrm{B}}$, NMDA, and AMPA receptors, respectively. Ionotropic glutamatergic EPSPs were evoked in isolation by bath application of $1 \mu \mathrm{M}$ CGP55845 and $20 \mu \mathrm{M}$ 6-imino-3-(4-methoxyphenyl)-1(6H)-pyridazinebutanoic acid hydrobromide (GABAzine) to block $\mathrm{GABA}_{\mathrm{B}}$ and $\mathrm{GABA}_{\mathrm{A}}$ receptors, respectively. These neurotransmitter receptor blockers were obtained from Tocris Cookson (Ellisville, MO).

Synthetic synaptic conductance injection. Single or multiple synthetic (dynamic clamp) IPSPs (dIPSPs) or EPSPs (dEPSPs) were applied through the patch pipette using a synaptic module (SM-1) conductance injection amplifier (Cambridge Conductance, Cambridge, UK) (Robinson and Kawai, 1993). The dynamic conductance waveform for an IPSP ( $5 \mathrm{nS}$ peak conductance; monoexponential rise and decay; $\tau_{\text {rise }}=0.8 \mathrm{~ms}$, $\tau_{\text {decay }}=10 \mathrm{~ms}$; equilibrium potential, $-80 \mathrm{mV}$ ) was based on the magnitude and kinetics of $\mathrm{GABA}_{\mathrm{A}}$ receptor-mediated postsynaptic currents observed under voltage clamp and the equilibrium potential of $\mathrm{GABA}_{\mathrm{A}}$ IPSPs (Bevan et al., 2002a) in STN neurons. The dynamic conductance waveform underlying the synthetic AMPA-receptor mediated EPSP (2.5 $\mathrm{nS}$ peak conductance; monoexponential rise and decay; $\tau_{\text {rise }}=0.8 \mathrm{~ms}$, $\tau_{\text {decay }}=3.7 \mathrm{~ms}$; equilibrium potential, $0 \mathrm{mV}$ ) was also based on experimental measurements (data not shown). During dynamic-clamp experiments, series resistance was compensated to minimize the error in the recorded voltage during the injection of current.

To investigate the role of postsynaptic properties in the integration of synthetic synaptic conductances, the following drugs were applied: tetrodotoxin (TTX) (Tocris Cookson) to block $\mathrm{Na}_{\mathrm{v}}$ channels; ZD7288 (4-ethylphenylamino-1,2-dimethyl-6-methylaminopyrimidinium chloride) (Tocris Cookson) or $\mathrm{Cs}^{+}$to block $\mathrm{HCN}$ channels; and $\mathrm{Ni}^{2+}$ to block $\mathrm{Ca}_{\mathrm{v}} 3$ channels.

\section{Acute isolation and whole-cell voltage-clamp recordings}

Single slices were removed from the holding chamber and placed in a low $\mathrm{Ca}^{2+}$ solution containing the following (in mM): $140 \mathrm{Na}$ isethionate, 2 $\mathrm{KCl}, 4 \mathrm{MgCl}_{2}, 0.1 \mathrm{CaCl}_{2}, 23$ glucose, and 15 HEPES, pH adjusted to 7.2 with $\mathrm{NaOH}$ (300-310 mOsm). The STN was then dissected and transferred to a chamber containing HEPES-buffered HBSS (Sigma, St. Louis, $\mathrm{MO})$, $\mathrm{pH}$ adjusted to 7.35 with $\mathrm{NaOH}(300-310 \mathrm{mOsm})$, and $0.4 \mathrm{mg} / \mathrm{ml}$ protease type XIV for $30 \mathrm{~min}$ at $35^{\circ} \mathrm{C}$. The tissue was then washed several times in low-Ca ${ }^{2+}$ buffer and mechanically dissociated using firepolished glass pipettes. The suspension of neurons was allowed to settle in a cell culture dish mounted to the stage of an inverted microscope.

Neurons were then perfused with a background solution containing the following (in mM): $140 \mathrm{NaCl}, 23$ glucose, 15 HEPES, $2 \mathrm{KCl}, 2 \mathrm{MgCl}_{2}$, and $1 \mathrm{CaCl}_{2}$, pH 7.2 (300-310 mOsm). Whole-cell voltage-clamp recordings were obtained at room temperature using glass micropipettes (3-6 M $\Omega$ ) filled with the following (in mM): $130 \mathrm{~N}$-methyl-D-glucamine, 20 HEPES, $20 \mathrm{CsCl}, 2 \mathrm{MgCl}_{2}, 1 \mathrm{Na}_{4}$ EGTA, 12 phosphocreatine, 2 $\mathrm{Mg}_{1.5} \mathrm{ATP}, 0.4 \mathrm{Na}_{3} \mathrm{GTP}$, and 0.1 leupeptin, $\mathrm{pH}$ adjusted to 7.2 with $\mathrm{CsOH}$ (270-275 mOsm). $\mathrm{Na}_{\mathrm{v}}$ channel currents were isolated by subtracting currents recorded in the presence of $500 \mathrm{nM}$ TTX from currents recorded in control external solution, which contained the following (in $\mathrm{mm}): 115 \mathrm{NaCl}, 45$ tetraethylammonium-Cl, $10 \mathrm{HEPES}, 10 \mathrm{CsCl}, 1$ $\mathrm{MgCl}_{2}, 2 \mathrm{CaCl}_{2}$, and $0.3 \mathrm{CdCl}, \mathrm{pH}$ adjusted to 7.3 with $\mathrm{NaOH}(300-305$ mOsm). Data were recorded using an Axopatch 200B amplifier (digitized at $50 \mathrm{kHz}$, low-pass filtered at $10 \mathrm{kHz}$ ) controlled by Clampex 9.0 . Series resistances of $\sim 7-15 \mathrm{M} \Omega$ were electrically compensated by $\sim 85 \%$, and a junction potential of $4 \mathrm{mV}$ was accounted for in all of the voltage-clamp waveforms that were applied. 
A(i)
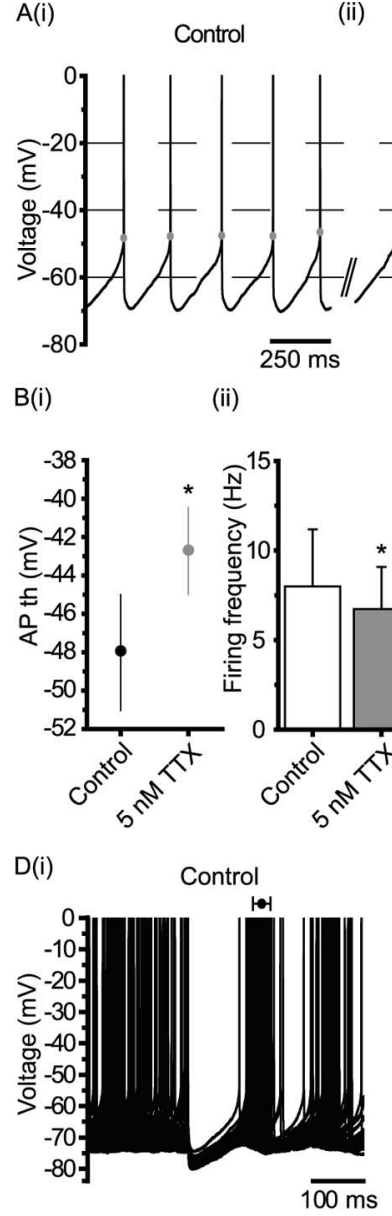

(ii)

(ii)

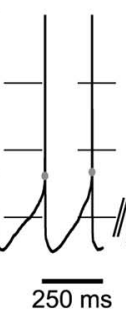

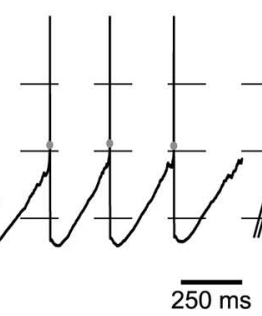

$\mathrm{C}(\mathrm{i})$
$5 \mathrm{nM} T \mathrm{TX}$

(iii) Recovery saturating $\Pi \mathrm{X}$

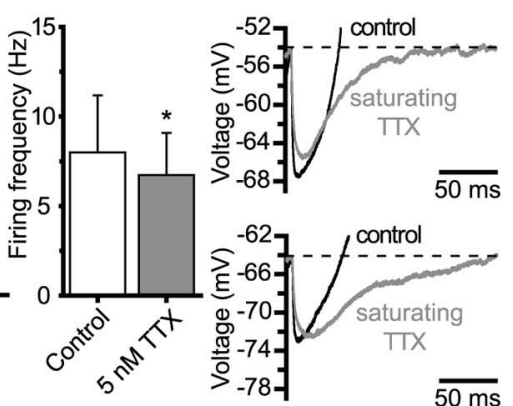

(iii)

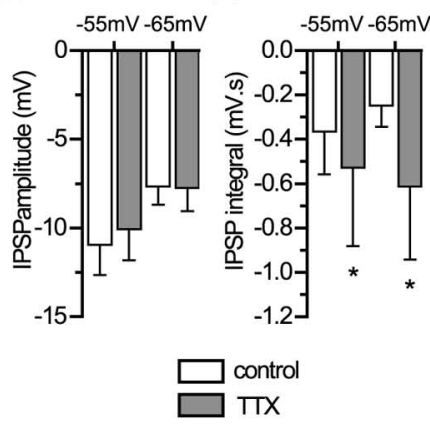

(ii)

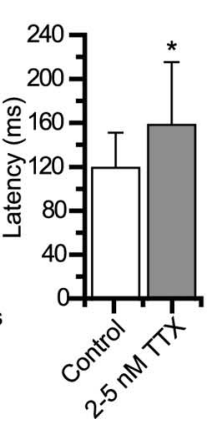

(iii)

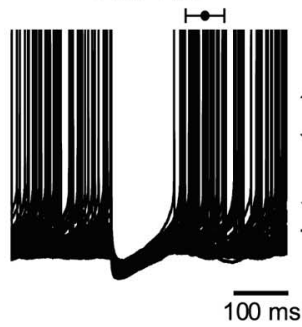

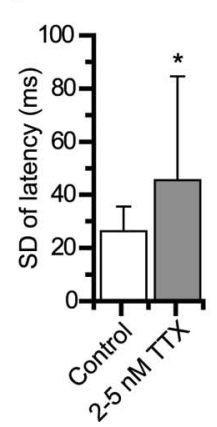

Figure 1. $\mathrm{Na}_{v}$ channels pace autonomous activity and participate in inhibitory synaptic integration. Selective blockade of $\sim 47 \% \mathrm{Na}_{\mathrm{v}}$ channels with $5 \mathrm{~nm}$ TTX elevated APth and reduced the frequency of firing in a reversible manner (Ai-Aiii, individual example; $\boldsymbol{B i}$, Bii, population data; $n=7$ ). Aiv, Complete blockade of $\mathrm{Na}_{v}$ channels abolished firing and led to a stable membrane potential below APth (inset in Aiv, sensitivity of peak $\mathrm{Na}^{+}$current evoked by a $50 \mathrm{~ms}$ step from -90 to $-45 \mathrm{mV}$ to TTX in acutely isolated STN neurons; $n=6$ ). The amplitude of dIPSPs measured at approximately $-55 \mathrm{mV}$ and approximately $-65 \mathrm{mV}$ was not altered, but their integral was increased by the application of saturating concentrations of TTX ( $C$, representative examples at -54 and $-64 \mathrm{mV}$; (ii-Ciii, population data; $n=9$ ). D, A partial reduction in $\mathrm{Na}_{\mathrm{v}}$ channel availability with $2-5 \mathrm{~nm}$ TTX affected the resetting of autonomous activity by GABA receptor-mediated dIPSPS. Di, Superimposition of 50 trials in control and low TTX conditions. The mean and SD of the latency of APs after the dIPSP for this example are shown at the top of each graph. Dii, Diii, Population data illustrating that a decrease in $\mathrm{Na}_{\mathrm{v}}$ channel availability increases the latency (Dii) and reduces the precision (Diii; SD of latency) of APs generated after dIPSPs $(n=11) .{ }^{*} p<0.05$. All recordings were performed in the presence of ionotropic glutamate and GABA receptor antagonists (50 $\mu \mathrm{m}$ APV, $20 \mu \mathrm{m}$ DNQX, $20 \mu \mathrm{m}$ GABAzine, and 1-2 $\mu \mathrm{m}$ CGP55845).

Analysis

Data were analyzed using Origin 7.0 (Microcal Software, Northampton, MA). AP threshold (APth) was detected using a custom algorithm (available on request) that detected the first point of sustained positive "acceleration" of voltage $[(\delta V / \delta t) / \delta t]$ and was also more than two times the SD of membrane noise before APth.

\section{Statistics}

Because the current-clamp experiments were associated with small sample sizes of unknown distribution, paired [Wilcoxon's signed rank (WSR) test] and unpaired [Mann-Whitney $U(\mathrm{M}-\mathrm{W} U)$ test] nonparametric statistical tests were applied. Descriptive statistics in these experiments refer to mean $\pm \mathrm{SD}$. The sample sizes associated with voltageclamp experiments were larger, and, because the data were normally distributed, a paired parametric statistical test (Student's $t$ test) was used. Descriptive statistics in these experiments refer to mean \pm SEM. $p$ values that were $<0.05$ after they had been Bonferroni corrected for multiple comparisons ( $p$ value was multiplied by the number of comparisons) were considered significant.

\section{Results}

$\mathrm{Na}_{\mathrm{v}}$ channels pace autonomous activity and shape inhibitory synaptic integration

Although it is generally thought that there is a large reserve of $\mathrm{Na}_{\mathrm{v}}$ channels for the generation of APs, this reserve can decline considerably during repetitive activity as a result of $\mathrm{Na}_{\mathrm{v}}$ channel inactivation (Madeja, 2000; Do and Bean, 2003). To test how sensitive the autonomous activity of STN neurons was to a reduction in $\mathrm{Na}_{\mathrm{v}}$ channel availability, a subsaturating concentration of TTX was applied to slices during perforated patch recording. A concentration of $5 \mathrm{~nm}$ was selected because dose-response studies in acutely isolated STN neurons revealed that this concentration of TTX reduced the peak $\mathrm{Na}^{+}$current (elicited by a $50 \mathrm{~ms}$ step from -90 to -45 $\mathrm{mV}$ ) by approximately one-half (47\%) (Fig. 1 Aiv, inset). When applied to slices, 5 nM TTX caused a significant elevation of APth by $5.3 \pm 2.2 \mathrm{mV}$ (WSR test; control APth, $-48.1 \pm 3.1 \mathrm{mV} ; 5 \mathrm{nM}$ TTX APth, $-42.8 \pm 2.2 \mathrm{mV} ; n=6 ; p=0.031$ ) (Fig. $1 \mathrm{Ai}, \mathrm{Aii}, \mathrm{Bi})$ and a reduction in the frequency of AP generation of $15.9 \%$ (WSR test; control, $8.0 \pm 3.3 \mathrm{~Hz} ; 5 \mathrm{nM}$ TTX, $6.7 \pm 2.3 ; n=6 ; p=0.031$ ) (Fig. 1 Bii). In accordance with previous observations (Bevan and Wilson, 1999; Beurrier et al., 2000; Do and Bean, 2003), the complete blockade of $\mathrm{Na}_{\mathrm{v}}$ channels with a saturating concentration of TTX $(0.2-1 \mu \mathrm{M})$ abolished the membrane potential oscillation and resulted in a stable potential $7.2 \pm 3.3$ $\mathrm{mV}$ below APth (WSR test; APth, $-43.2 \pm 3.3 \mathrm{mV}$; resting potential in $1 \mu \mathrm{M}$ TTX, $-50.4 \pm 5.3 \mathrm{mV} ; n=7 ; p=0.015$ ) (Fig. 1Ai,Aiv). These data confirm that $\mathrm{Na}_{\mathrm{v}}$ channels, as the primary effectors of depolarization in the interspike interval, are required to reach APth in STN neu- rons. Moreover, an alteration in the availability of $\mathrm{Na}_{\mathrm{v}}$ channels strongly affects the generation of APs and AP morphology.

In cortical neurons, deactivation of $\mathrm{Na}_{\mathrm{v}}$ channels boosted the magnitude and integral of synthetic IPSPs through a reduction in persistent TTX-sensitive $\mathrm{Na}^{+}$current and an associated increase in membrane resistance (Stuart, 1999). In contrast to this finding, $0.2-1 \mu \mathrm{M}$ TTX produced no change in the peak amplitude of dIPSPs generated using a $\mathrm{GABA}_{\mathrm{A}}$ conductance waveform (Robinson and Kawai, 1993) compared with control conditions [(WSR test; $V_{\mathrm{m}}=-55 \mathrm{mV}$; control, $-11.0 \pm 1.7 \mathrm{mV}$; saturating TTX, $-10.0 \pm 1.8 \mathrm{mV} ; n=9 ; p=0.121)$ (Fig. 1Ci,Cii) $\left(V_{\mathrm{m}}=\right.$ $-65 \mathrm{mV}$; control, $-7.7 \pm 1.0 \mathrm{mV}$; saturating TTX, $-7.7 \pm 1.3$ $\mathrm{mV} ; n=9 ; p=0.82$ (Fig. 1Ci,Cii)] but did significantly increase the integral of dIPSPs generated at $-55 \mathrm{mV}$ [(WSR test; $V_{\mathrm{m}}=-55$ 
$\mathrm{mV}$; control, $-0.36 \pm 0.19 \mathrm{mV} . \mathrm{s}$; saturating TTX, $-0.53 \pm 0.35$ $\mathrm{mV} . \mathrm{s} ; n=9 ; p=0.0195$ ) (Fig. 1 Ci,Ciii) $]$ and $-65 \mathrm{mV}$ [(WSR test; $V_{\mathrm{m}}=-65 \mathrm{mV}$; control, $-0.25 \pm 0.10 \mathrm{mV} . \mathrm{s}$; saturating TTX, $-0.61 \pm 0.33 \mathrm{mV} . \mathrm{s} ; n=9 ; p=0.0039$ ) (Fig. 1Ci,Ciii)], indicating that postsynaptic $\mathrm{Na}_{\mathrm{v}}$ channels actively truncate IPSPs in STN neurons.

Because $\mathrm{GABA}_{\mathrm{A}}$ receptor-mediated IPSPs can precisely reset the phase of autonomous activity in STN neurons (Bevan et al., 2002a), the role of postsynaptic $\mathrm{Na}_{\mathrm{v}}$ channels in synaptic resetting was assessed through the impact of an $\sim 20-50 \%$ reduction in $\mathrm{Na}_{\mathrm{v}}$ channel availability (2-5 nM TTX, respectively) (Fig. 1D). The ability of dIPSPs to precisely reset autonomous oscillation was significantly altered by subsaturating concentrations of TTX, leading to an increase in the latency [WSR test; control, $119.5 \pm$ $32.0 \mathrm{~ms} ; 2-5$ nм TTX, $158.3 \pm 57.0 \mathrm{~ms} ; n=11 ; p=0.0137$ (Fig. $1 \mathrm{Di}, \mathrm{Dii})$ ] and variability [SD of latency; control, $26.1 \pm 9.2 \mathrm{~ms}$; $2-5$ nм TTX, $45.3 \pm 39.1 \mathrm{~ms} ; n=11 ; p=0.0137$ (Fig. 1 Di,Diii)] of the AP generated after the dIPSP. The distinct effects of $\mathrm{Na}_{\mathrm{v}}$ channel blockade on inhibitory synaptic integration in cortical and STN neurons presumably reflect differences in the properties of $\mathrm{Na}_{\mathrm{v}}$ and other channels in the two cell types and the fact that STN neurons discharge spontaneously whereas cortical pyramidal neurons rest $20-30 \mathrm{mV}$ below APth in the absence of synaptic input. Together, these data suggest a critical role for $\mathrm{Na}_{\mathrm{v}}$ channels in autonomous activity and synaptic integration at subthreshold voltages in STN neurons.

$\mathrm{HCN}$ and $\mathrm{Ca}_{\mathrm{v}} 3$ channels are not required for autonomous activity and are not greatly involved in the integration of single IPSPs

In sensory thalamic neurons and GP neurons, $\mathrm{HCN}$ channels are important contributors to pacemaking activity (McCormick and Bal, 1997; Robinson and Siegelbaum, 2003; Chan et al., 2004) and to the resetting of rhythmic firing by GABAergic synaptic inputs (McCormick and Bal, 1997; Chan et al., 2004). To assess their involvement in the firing of STN neurons, we used perforated patch-clamp recordings of STN neurons in the presence of synaptic transmission blockers (50 $\mu \mathrm{M}$ APV, $20 \mu \mathrm{M}$ CNQX, $20 \mu \mathrm{M}$ GABAzine, and 1-2 $\mu \mathrm{M}$ CGP55845) and during perfusion of 2 mM external $\mathrm{Cs}^{+}$to block HCN channels. In contrast to GP neurons (Chan et al., 2004) and in agreement with previous findings (Bevan and Wilson, 1999; Beurrier et al., 2000; Do and Bean, 2003), blockade of $\mathrm{HCN}$ channels with $\mathrm{Cs}^{+}$did not affect the firing rate of STN neurons [WSR test; control, $6.3 \pm 2.8 \mathrm{~Hz}$; Cs ${ }^{+}$, $6.3 \pm 3.3 \mathrm{~Hz} ; n=6 ; p=0.84$ (Fig. $2 \mathrm{Ai}, \mathrm{Aii}, \mathrm{Bi}$ )]. Moreover, $\mathrm{Cs}^{+}$ did not disrupt the rhythmicity of autonomous activity [WSR test; coefficient of variation $(\mathrm{CV})$ control, $0.08 \pm 0.03$; $\mathrm{CV} \mathrm{Cs}^{+}$, $0.06 \pm 0.02 ; n=6 ; p=0.062$ (Fig. 2Ai,Aii, Bii)].

In STN and GP neurons, stimulation of GABAergic IPSPs transiently hyperpolarizes the membrane potential and produces a pause in firing and a partial or complete reset of the phase of the autonomous oscillation (Bevan et al., 2002a; Chan et al., 2004). In GP neurons, blockade of $\mathrm{HCN}$ channels disrupted phase resetting. Whether single IPSPs also recruit HCN channels in STN neurons has not been tested. Because blockade of HCN channels located on presynaptic terminals can affect the probability of neurotransmitter release (Beaumont and Zucker, 2000; Chevaleyre and Castillo, 2002), somatic dIPSPs were used. In six neurons, the mean latency and precision of the AP (SD of the latency) after the dIPSP were unchanged by $\mathrm{Cs}^{+}$treatment [WSR test; latency control, $123.8 \pm$ $50.3 \mathrm{~ms}$; latency $\mathrm{Cs}^{+}, 130.4 \pm 47.3 \mathrm{~ms} ; n=6 ; p=0.843$; SD of latency control, $29.4 \pm 17.1 \mathrm{~ms}$; SD of latency $\mathrm{Cs}^{+}, 32.8 \pm 17.4$ ms; $n=6 ; p=0.09$ (Fig. 2Ci,Cii,Di,Dii)]. The effects of HCN
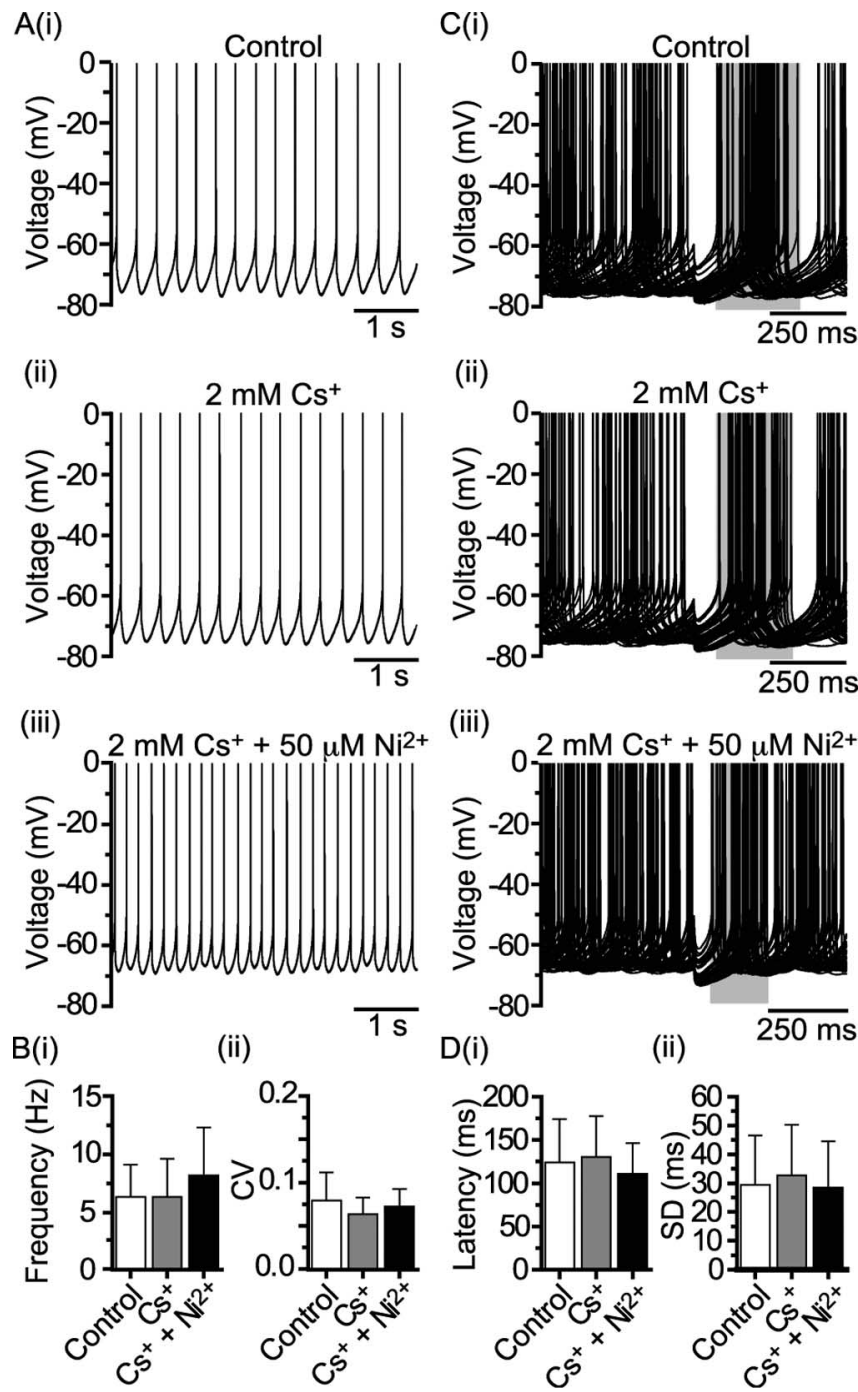

Figure 2. $\mathrm{HCN}$ and $\mathrm{Ca}_{\mathrm{v}} 3$ channels are not essential for autonomous activity and do not participate in the resetting of oscillations by GABAergic IPSPS. $\boldsymbol{A}$, Impact of $\mathrm{Cs}^{+}$and $\mathrm{Ni}^{2+}$ treatments on autonomous activity in STN neurons. Ai-Aiii, Individual examples of $5 \mathrm{~s}$ of spontaneous firing in control conditions $(\boldsymbol{I})$, the absence of effect of $\mathrm{Cs}^{+}$on autonomous firing (ii), and the increase in autonomous firing frequency in the presence of $50 \mu \mathrm{m} \mathrm{Ni}{ }^{2+}$ (iii). Bi, Bii, Summary of the effect of $\mathrm{Cs}^{+}$and $\mathrm{Ni}^{2+}$ on the frequency $(\boldsymbol{i})$ and precision $(\mathrm{CV} ; \boldsymbol{i}$ i) of autonomous oscillation in six neurons. $\boldsymbol{C}$, Blockade of $\mathrm{HCN}$ and $\mathrm{Ca}_{\mathrm{v}} 3$ channels had no effect on the resetting of oscillations by $G_{A B A_{A}}$ receptor-mediated IPSPs. Ci-Ciii, Superimposition of 50 trials showing resetting by dIPSPs in control conditions (i), in the presence of $\mathrm{Cs}^{+}(\boldsymbol{i i})$, and in the presence of $\mathrm{Cs}^{+}$and $\mathrm{Ni}^{2+}$ (iii). Time windows of AP generation after dIPSPs are depicted by gray rectangles. Di, Dii, Population data demonstrating that $\mathrm{HCN}$ and $\mathrm{Ca}_{v} 3$ channel blockade did not alter the latency (i) and precision (ii; SD of the latency) of APs generated after dIPSPs ( $n=6)$.

channel blockade on the resetting of autonomous oscillation by electrically stimulated IPSPs $(n=4)$ and $\operatorname{dIPSPs}(n=3)$ were also tested using the selective HCN channel blocker ZD7288 $(20 \mu \mathrm{M})$. Because no clear differences were observed between IPSPs (supplemental Fig. $1 A$, available at www.jneurosci.org as supplemental material) and dIPSPs (supplemental Fig. $1 B$, available at www.jneurosci.org as supplemental material), data were pooled. As with $\mathrm{Cs}^{+}$treatment, no significant change in the latency (WSR test; latency control, $116.5 \pm 41.1 \mathrm{~ms}$; latency $20 \mu \mathrm{M}$ ZD7288, $131.5 \pm 52.0 \mathrm{~ms} ; n=7 ; p=0.468$ ) or precision (WSR test; SD of latency control, $24.5 \pm 10.7 \mathrm{~ms}$; SD of latency $20 \mu \mathrm{M}$ ZD7288, $29.5 \pm 14.3 \mathrm{~ms} ; n=7 ; p=0.578$ ) of the AP after the IPSP or 
dIPSP was observed (supplementary Fig. 1, available at www. jneurosci.org as supplemental material).

mRNA encoding all four subtypes of HCN channels (HCN1HCN4) have been detected in the STN of rodents, but only HCN2 displayed a high level of expression (Monteggia et al., 2000; Santoro et al., 2000). The time constants of activation of recombinant and native HCN2 channels are in the hundreds of milliseconds range (Ludwig et al., 1999; Santoro et al., 2000), which is an order of magnitude longer than the decay time constant of $\mathrm{GABA}_{\mathrm{A}}$ receptor-mediated IPSPs in STN neurons. On the basis of the biophysical properties of HCN channels in STN neurons and the nonsignificant effects of HCN channel blockade, we conclude that HCN channels contribute little to the integration of single IPSPs.

Subsequent to $\mathrm{HCN}$ channel blockade by $\mathrm{Cs}^{+}, 50-100 \mu \mathrm{M}$ $\mathrm{Ni}^{2+}$ was added in the bath to block $\mathrm{Ca}_{\mathrm{v}} 3$ channels, which are known to contribute greatly to rhythmic activity and inhibitory synaptic integration in sensory thalamic neurons (Huguenard, 1996; McCormick and Bal, 1997). The mean firing frequency increased by $30.2 \%$, but, as a population, this effect was not significant [WSR test; control, $6.3 \pm 2.8 \mathrm{~Hz} ; \mathrm{Ni}^{2+}, 8.2 \pm 4.2 \mathrm{~Hz} ; n=$ $6 ; p=0.093$ (Fig. 2Ai,Aiii,Bi)]. The rhythmicity (CV) of autonomous activity was also not significantly altered compared with control conditions [WSR test; control, $0.08 \pm 0.03 ; \mathrm{Ni}^{2+}, 0.07 \pm$ $0.02 ; n=6 ; p=1$ (Fig. 2Bii)]. The latency of AP generation after dIPSPs [WSR test; control, $123.8 \pm 50.4 \mathrm{~ms} ; \mathrm{Ni}^{2+}, 110.7 \pm 35.6$ $\mathrm{ms} ; n=6 ; p=0.3125$ (Fig. $2 \mathrm{Ci}, \mathrm{Ciii}, \mathrm{Di}$ ) $]$ and the precision of AP generation after IPSPs were unaffected by $\mathrm{Ni}^{2+}$ treatment [SD of latency; control, $29.4 \pm 17.1 \mathrm{~ms} ; \mathrm{Ni}^{2+}, 28.5 \pm 16.1 \mathrm{~ms} ; n=6 ; p=$ 0.687 (Fig. 2Ci,Ciii,Dii)]. $\mathrm{Ca}_{\mathrm{v}} 3$ channels are responsible for the postinhibitory depolarization that leads to a burst of APs called a "rebound burst" in STN and other neurons (Nakanishi et al., 1987; Overton and Greenfield, 1995; Huguenard, 1996; McCormick and Bal, 1997; Beurrier et al., 1999; Bevan and Wilson, 1999; Bevan et al., 2000, 2002a; Song et al., 2000). To generate a rebound burst in STN neurons, the membrane potential must be hyperpolarized for several tens of milliseconds for sufficient deinactivation of $\mathrm{Ca}_{\mathrm{v}} 3$ channels (Huguenard, 1996; McCormick and Bal, 1997; Kuo and Yang, 2001), which requires a relatively highfrequency barrage of summating IPSPs (Bevan et al., 2002a). Together, our observations and the known biophysical properties of $\mathrm{Ca}_{\mathrm{v}} 3$ channels in STN and other neurons indicate that $\mathrm{Ca}_{\mathrm{v}} 3$ channels do not participate in the integration of single IPSPs in STN neurons. The increase in the frequency of autonomous activity that was obtained with $\mathrm{Ni}^{2+}$ application in five of six STN neurons supports the existence of $\mathrm{Ca}_{\mathrm{v}} 3$ channel-mediated $\mathrm{Ca}^{2+}$ influx during autonomous firing (Williams et al., 1997; Chemin et al., 2002). The increase in firing frequency that accompanies the blockade of an inward $\mathrm{Ca}^{2+}$ current may indicate that $\mathrm{Ca}_{\mathrm{v}} 3$ channels are functionally coupled to small and/or large conductance $\mathrm{Ca}^{2+}$-activated potassium channels (cf. Smith et al., 2002; Wolfart and Roeper, 2002; Hallworth et al., 2003).

\section{GABAergic IPSPs transiently reduce APth and increase the rate of rise of APs}

$\mathrm{GABA}_{\mathrm{A}}$ receptor-mediated IPSPs were evoked in STN neurons by electrical stimulation of putative GP axons in the internal capsule. As described previously, low-frequency trains of IPSPs (Fig. 3Ai) and single IPSPs (Fig. 3Bi) invariably interrupted autonomous activity without an augmentation in subsequent activity (Bevan et al., 2002a). However, closer inspection of these recordings revealed that APs generated immediately after IPSPs were modified (Fig. $3 A, B$ ). Figure $3 A$ iii shows a graphical repre-
A(i)

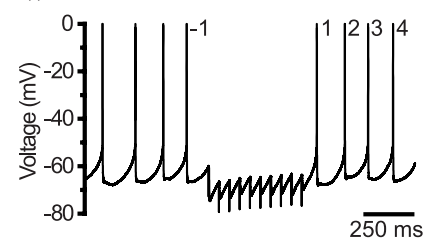

(ii)

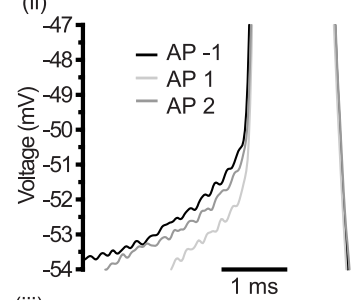

(iii)

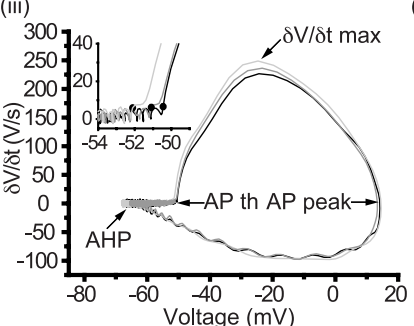

(iv)
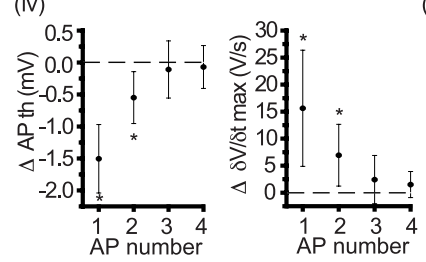

(iv)

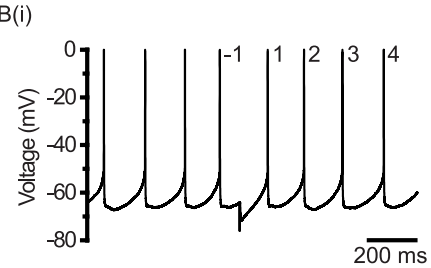

(ii)

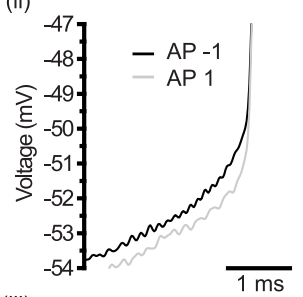

(iii)
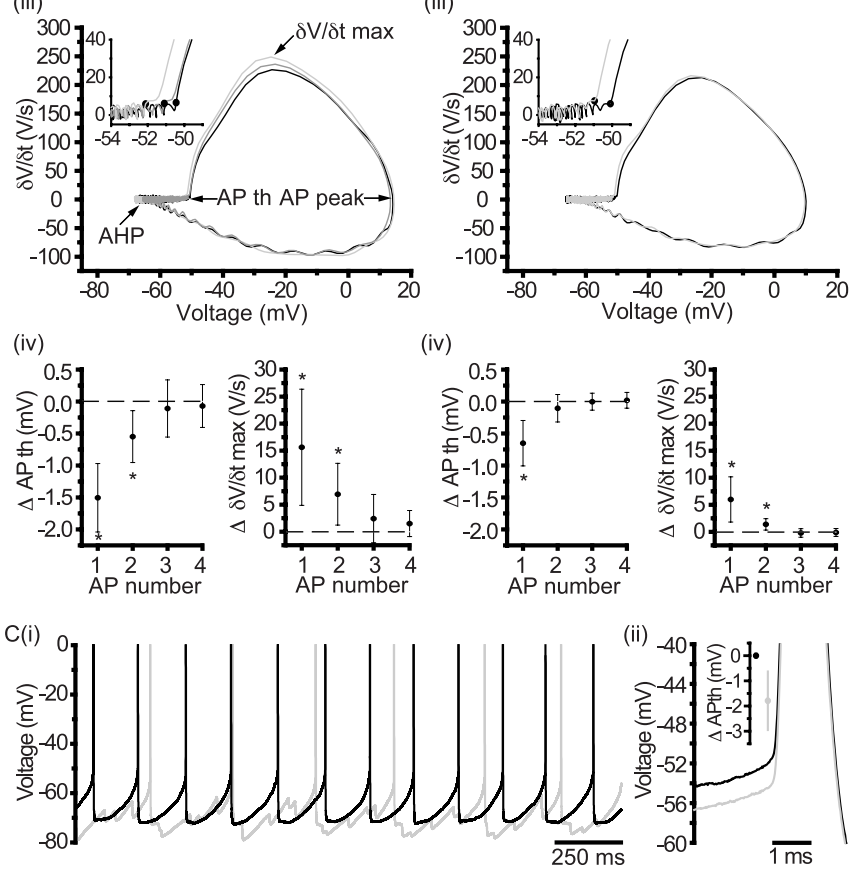

Figure 3. $G A B A_{A} I P S P s$ modify the morphologies of APs. $A$, Multiple electrically stimulated IPSPs (Ai) lowered threshold (Aii-Aiv) and increased the maximal speed (Aiii, Aiv) of APs generated after IPSPs. Aii, Overlaid APs generated before (AP -1) and after (AP 1, AP 2) multiple IPSPs. Aiii, Plots of $(\delta V / \delta t) / V$ illustrate the method used to measure APth (defined as first point of sustained positive acceleration of voltage $[(\delta V / \delta t) / \delta t]$ that was also $>2$ times the SD of membrane noise before APth) and the maximal speed [( $\delta V / \delta t)$ max $]$ of APs. Other characteristic features of APs on the phase plot, such as the spike afterhyperpolarization (AHP) and the peak of the AP, are also noted. Inset, Zoom of APths (dots). Aiv, Population sample of the IPSP-induced changes in APth and maximal speeds of APs $(n=9)$. $\boldsymbol{B}$, Single electrically stimulated IPSPs (Bi) lowered APth (Bii-Biv) and increased the maximal speed of APs (Biii, Biv) generated after an IPSP in the same neuron. Bii, Overlaid APs generated before (AP -1$)$ and after (AP 1) an IPSP. Biii, Phase plot showing APth. Insets, Zoom of APths (dots). Biii, Population sample of the change in APth and maximal speed of APs $(n=9)$. Larger effects were observed in individual neurons (Ai-Aiiii vs Bi-Biiii) and across the population sample (Aiv vs Biv) after multiple IPSPs. C, Spontaneous IPSPs modified APths in a similar manner to electrically stimulated IPSPs or dIPSPS. Ci, Example of autonomous activity with (gray trace) and without (black trace; IPSPs blocked by GABAzine) spontaneous IPSPs in the same neuron. Cii, Overlaid APs in each condition. Inset, Mean APth in the presence and absence of spontaneous inhibition $(n=3) .{ }^{*} p<0.05$.

sentation of the method used to examine APs. In this phase plot $[(\delta V / \delta t) / V]$, the peak of the action potential and the base of the afterhyperpolarization potential have a $\delta V / \delta t$ of 0 , and the point of positive inflection corresponds to APth. After a train of 10 IPSPs at $20 \mathrm{~Hz}$ or after a single IPSP, APth was hyperpolarized 
relative to the previous $\mathrm{AP}$, as indicated by the leftward shift in the point of inflection of the AP after inhibition (Fig. 3Aiii,Biii, insets, APths are indicated by dots). The APth of the first AP after inhibition was significantly hyperpolarized by $1.5 \pm 0.5$ $\mathrm{mV}$ (WSR test; APth before IPSPs, $-48.7 \pm 2.8 \mathrm{mV}$; APth after IPSPs, $-50.2 \pm 2.8 \mathrm{mV} ; n=9 ; p=0.0039)$ and $0.7 \pm 0.4 \mathrm{mV}$ (WSR test; APth before IPSP, $-47.3 \pm 3.0 \mathrm{mV}$; APth after IPSP, $-48.0 \pm 3.1 \mathrm{mV} ; n=9 ; p=0.0039)$ after a train of IPSPs (Fig. 3Aiv, left graph) and a single IPSP (Fig. 3Biv, left graph), respectively. Another AP parameter that was modified by synaptic inhibition was the maximal rate of rise of APs (Fig. 3Aiv, Biv, right graph). Multiple and single IPSPs produced an increase of $15.6 \pm 10.7 \mathrm{Vs}^{-1}$ (WSR test; before IPSPs, $219.4 \pm 72.8$ $\mathrm{Vs}^{-1}$; after IPSPs, $235.0 \pm 81.6 \mathrm{Vs}^{-1} ; n=$ $9 ; p=0.0039)$ and of $6.0 \pm 4.2 \mathrm{Vs}^{-1}$ (WSR test; before IPSP, $260.9 \pm 79.9 \mathrm{Vs}^{-1}$; after IPSP, $266.9 \pm 82.9 \mathrm{Vs}^{-1} ; n=9 ; p=$ $0.0039)$ in the maximal rate of rise of the subsequent APs, respectively (Fig. $3 A i v$, Biv, right graph). The larger changes produced by multiple IPSPs compared with single IPSPs in APth (M-W $U$ test; AP1: train of IPSPs, $1.5 \pm 0.5 \mathrm{mV}$; single IPSP, $0.7 \pm 0.4 \mathrm{mV} ; p=0.0019$; AP2: train of IPSPs, $0.5 \pm 0.4 \mathrm{mV}$; single IPSP, $0.1 \pm$ $0.2 \mathrm{mV} ; p=0.0315)$ and maximal rate of rise of the AP (M-W $U$ test; AP1: train of IPSPs, $15.6 \pm 10.7 \mathrm{Vs}^{-1}$; single IPSP, $6.0 \pm 4.2 \mathrm{Vs}^{-1} ; p=0.0019 ; \mathrm{AP} 2$ : train of IPSPs, $6.9 \pm 5.7 \mathrm{Vs}^{-1}$; single IPSP, $1.4 \pm$ $1.1 \mathrm{Vs}^{-1} ; p=0.04$ ) indicated that AP dynamics were modified in a manner that reflected the duration of preceding inhibition (Fig. 3Aiv,Biv).

dIPSPs produced similar effects on APs (supplemental Fig. 2, available at www.jneurosci.org as supplemental material), suggesting that somatic GABAergic inputs that are known to arise from the GP (Smith et al., 1990; Bevan et al., 1997) are sufficient for AP modification. As observed with synaptic IPSPs, multiple dIPSPs modified subsequent APs to a greater extent than single IPSPs (results shown graphically in supplemental Fig. 2iv).

Spontaneous GABAergic IPSPs were also observed in some recordings, suggesting a certain degree of connectivity between GP and STN neurons within the slice (Fig. 3Ci). After spontaneous IPSPs were blocked with $20 \mu \mathrm{M}$ GABAzine, the firing frequency increased by $46.6 \%$ (control, $3.9 \pm 2.3 \mathrm{~Hz}$; GABAzine, $5.7 \pm 2.3 \mathrm{~Hz} ; n=3)$, and the APth was depolarized by $1.8 \pm 1.2$ $\mathrm{mV}$ [control, $-49.0 \pm 4.7 \mathrm{mV}$; GABAzine, $-47.2 \pm 3.6 \mathrm{mV} ; n=$ 3 (Fig. 3Cii)] in all three cells tested. These observations are in accordance with the effects of evoked and dIPSPs. Because the magnitudes of spontaneous events were similar to the magnitudes of IPSPs generated by electrical stimulation or conductance injection, the data suggest that the activity of a few inhibitory axons is sufficient for the modification of APs. Because APth and the rate of rise of APs are determined in large part by $\mathrm{Na}_{\mathrm{v}}$ channels (Hodgkin and Huxley, 1952; Mainen and Sejnowski, 1995), our
A(ii)

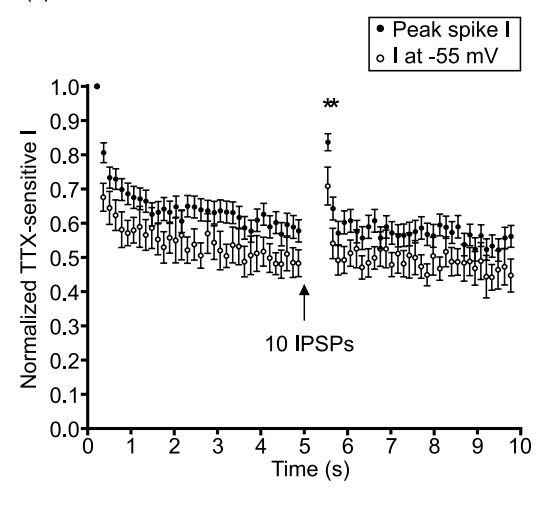

B(ii)

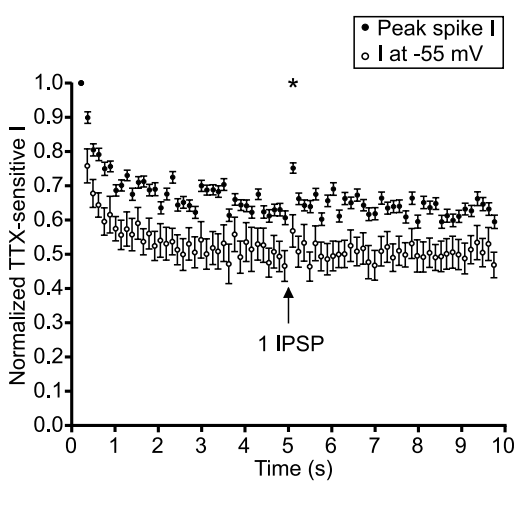

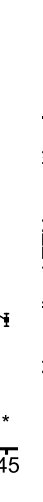

$\mathrm{V}(\mathrm{mV})$

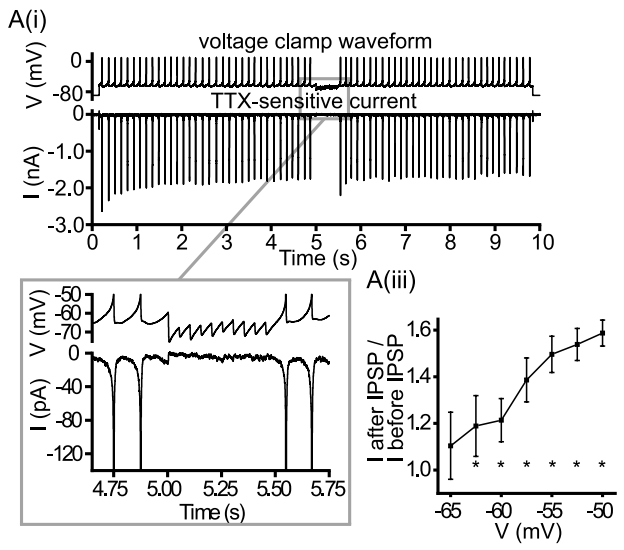

Figure 4. Inactivation of $\mathrm{Na}_{\mathrm{v}}$ channels during autonomous activity is relieved in a duration-dependent manner by IPSPS. Autonomous spiking and inhibitory activity recorded using the perforated patch-clamp technique was replayed to acutely isolated

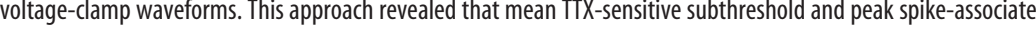

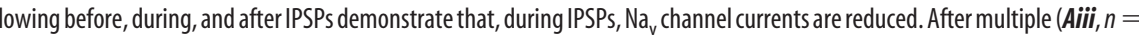
) and single (Biii, $n=16$ ) IPSPs, subthreshold current was significantly increased throughout the range of voltages traversed during the interspike interval. ${ }^{*} p<0.05$. I, Current; V, voltage.

observations suggest that IPSPs recovered $\mathrm{Na}_{\mathrm{v}}$ channels from nonconducting states and increased the availability of $\mathrm{Na}_{\mathrm{v}}$ channels for the subsequent generation of APs.

\section{GABAergic IPSPs deactivate and deinactivate $\mathrm{Na}_{\mathrm{v}}$ channels}

To quantify the impact of IPSPs on $\mathrm{Na}_{\mathrm{v}}$ channel availability, current-clamp traces from experiments in which trains (Fig. $4 \mathrm{Ai}$ Aiii) or single (Fig. 4Bi-Biii) IPSPs had been evoked were replayed as voltage-clamp waveforms in acutely isolated STN neurons. Between trials, neurons were held at $-90 \mathrm{mV}$ to ensure maximal $\mathrm{Na}_{\mathrm{v}}$ channel availability. The $\mathrm{Na}^{+}$currents evoked by these waveforms were isolated by subtraction of currents evoked in the presence of TTX from control currents (Fig. 4). The AP waveform elicited robust spike-associated TTX-sensitive currents (several hundred picoamperes to less than $1.5 \mathrm{nA}$ ) that declined rapidly to a few picoamperes at the foot of each spike. During the interspike interval, subthreshold $\mathrm{Na}^{+}$current then increased steadily until the threshold of each AP was reached. In line with previous reports, resurgent $\mathrm{Na}^{+}$current that flows during action potential repolarization had a relatively minimal contribution in terms of current magnitude compared with the larger $\mathrm{Na}^{+}$current that flows during the slow ramp depolarization be- 
tween APs, which was presumably mediated by $\mathrm{Na}_{\mathrm{v}}$ channels that inactivated slowly (Do and Bean, 2003).

In accordance with previous observations, repetitive spiking produced significant inactivation of $\mathrm{Na}_{\mathrm{v}}$ channels (Do and Bean, 2003). Both peak spike-associated and subthreshold $\mathrm{Na}^{+}$currents declined with similar kinetics and to a similar degree. Delivery of IPSPs during these spike trains deactivated $\mathrm{Na}_{\mathrm{v}}$ channels (Fig. 4Ai,Bi, enlargements). Peak spike-associated $\mathrm{Na}^{+}$currents associated with the two APs (AP1 and AP2) after multiple IPSPs were boosted by $45.9 \pm 18.2$ and $10.0 \pm 2.6 \%$, respectively, compared with the currents flowing in the previous five oscillatory cycles [Student's $t$ test; mean normalized peak spike-associated $\mathrm{Na}^{+}$current before a train of IPSPs, $0.59 \pm 0.12$; mean normalized peak AP1-associated $\mathrm{Na}^{+}$current after a train of IPSPs, $0.84 \pm 0.09 ; n=13 ; p<0.001$; mean normalized peak AP2associated $\mathrm{Na}^{+}$current after a train of IPSPs, $0.64 \pm 0.12 ; n=13$; $p<0.001$ (Fig. 4Ai,Aii)]. Subthreshold $\mathrm{Na}^{+}$current measured in the first and second oscillatory cycles after multiple IPSPs were also boosted by $48.6 \pm 27.7$ and $11.3 \pm 9.5 \%$, respectively, compared with the currents flowing in the previous five oscillatory cycles [Student's $t$ test; mean normalized $\mathrm{Na}^{+}$current at $-55 \mathrm{mV}$ before a train of IPSPs, $0.49 \pm 0.14$; mean normalized $\mathrm{Na}^{+}$current at $-55 \mathrm{mV}$ in the first oscillatory cycle after a train of IPSPs, $0.71 \pm 0.20 ; n=13 ; p<0.001$; mean normalized $\mathrm{Na}^{+}$current at $-55 \mathrm{mV}$ in the second oscillatory cycle after a train of IPSPs, $0.54 \pm 0.16 ; n=13 ; p=0.005$ (Fig. 4Aii,Aiii)]. Similar boosting of subthreshold $\mathrm{Na}^{+}$current was also observed at a range of subthreshold voltages in the first oscillatory cycle after multiple IPSPs (Fig. 4Aiii).

Both the peak and the subthreshold currents associated with the first oscillatory cycle after a single IPSP were also significantly greater than the mean currents associated with the previous five oscillatory cycles. The mean peak spike-associated current and subthreshold current measured at $-55 \mathrm{mV}$ were amplified, respectively, by $21.8 \pm 7.8 \%$ [Student's $t$ test; mean normalized peak $\mathrm{Na}^{+}$current before a single IPSP, $0.62 \pm 0.06$; mean normalized peak $\mathrm{Na}^{+}$current after a single IPSP, $0.75 \pm 0.06 ; n=16$; $p<0.001$ (Fig. $4 B i, B i i$ ) ] and $18.2 \pm 12.8 \%$ [Student's $t$ test; mean normalized $\mathrm{Na}^{+}$current at $-55 \mathrm{mV}$ before a single IPSP, $0.49 \pm$ 0.16 ; mean normalized $\mathrm{Na}^{+}$current at $-55 \mathrm{mV}$ after a single IPSP, $0.58 \pm 0.18 ; n=16 ; p<0.001$ (Fig. 4Bii)]. Similar boosting of subthreshold $\mathrm{Na}^{+}$current was also observed at a range of subthreshold voltages after a single IPSP (Fig. 4 Biii).

The amplification of spike-associated and subthreshold currents in the oscillatory cycle immediately after multiple IPSPs (Fig. 4Aii,Aiii) was significantly greater than the same currents measured after a single IPSP (Fig. 4Bii,Biii) (peak spikeassociated current, $p<0.001$; subthreshold current at $-55 \mathrm{mV}$, $p<0.005)$. These data suggest that the tonic spiking of STN neurons is associated with the inactivation of $\mathrm{Na}_{\mathrm{v}}$ channels, which can be relieved transiently and in a duration-dependent manner by IPSPs.

\section{Recovery of $\mathrm{Na}_{\mathrm{v}}$ channels from inactivation enhances the integration of subsequent excitatory inputs}

A highly effective input sequence for producing precise and efficient generation of APs is brief inhibition followed by a rapid depolarizing event (Mainen and Sejnowski, 1995). The hypothesis advanced to explain this result was that inhibitory inputs, by relieving $\mathrm{Na}_{\mathrm{v}}$ channel inactivation, could transiently modify the integrative properties of neurons and thus enhance the efficacy with which subsequent excitatory inputs lead to the generation of APs. This proposal is in marked contrast to the widely held role of inhibition, i.e., reduction of the spatiotemporal extent of neuronal excitation arising from excitatory synaptic inputs (Connors, 1984; Fricker and Miles, 2000; Wehr and Zador, 2003).

The impact of IPSPs on excitatory synaptic integration was assessed through perforated patch-clamp recordings in which EPSPs were evoked by electrical stimulation of the internal capsule in the presence of GABA receptor antagonists (Fig. 5). The latency and precision of APs generated after EPSPs were compared in three protocols: EPSPs were evoked in isolation (Fig. $5 A i, A i i), 50-75 \mathrm{~ms}$ after dIPSPs (Fig. 5Bi,Bii), or simultaneously with dIPSPs (Fig. 5Ci,Cii). The mean latency of APs generated after EPSPs was significantly reduced when EPSPs were preceded by dIPSPs (EPSP alone, $49.3 \pm 20.3 \mathrm{~ms}$; EPSP preceded by a dIPSP, $22.0 \pm 12.0 \mathrm{~ms} ; n=7 ; p=0.015)$ but not when EPSPs were coincident with dIPSPs [EPSP coincident with dIPSP, $97.0 \pm 25.9 \mathrm{~ms} ; n=7$ (Fig. $5 A-D, F)]$. Furthermore, the precision with which APs were generated (SD of latency) was enhanced by dIPSPs when EPSPs were preceded by a dIPSP [EPSP alone, $34.3 \pm 15.6 \mathrm{~ms}$; EPSP preceded by a dIPSP, $12.3 \pm 6.3 \mathrm{~ms} ; n=7$; $p=0.015$ ) (Fig. 5G)] but not when they were coincident with a dIPSP [EPSP coincident with dIPSP, $23.5 \pm 10.4 \mathrm{~ms} ; n=7$ (Fig. $5 G)]$. The threshold of APs generated after an EPSP alone or coincident with a dIPSP was unchanged when compared with the preceding $\mathrm{AP}$ ( $\delta \mathrm{APth}$; EPSP alone, $-0.10 \pm 0.34 \mathrm{mV} ; n=7 ; p=$ 0.5781 ; EPSP coincident with IPSP, $-0.17 \pm 0.33 \mathrm{mV} ; n=7 ; p=$ 0.2188 ), which was in marked contrast with the $-1.18 \pm 0.87 \mathrm{mV}$ hyperpolarization of APth that was observed in the protocol in which EPSPs were preceded by dIPSPs $(n=7 ; p=0.015)$ (Fig. $5 E$ ). When dIPSPs were elicited in isolation, the following AP occurred with a latency of $65.6 \pm 23.5 \mathrm{~ms}$ and a precision (SD of latency) of $18.6 \pm 4.5 \mathrm{~ms}$ ( $n=7$; data not shown), which was greater than the precision found when an EPSP was evoked alone or coincidently with a dIPSP. In five of seven neurons, the precision of AP generation produced by an EPSP preceded by a dIPSP was better than the precision observed after inhibition alone (EPSP preceded by a dIPSP, $9.0 \pm 3.7 \mathrm{~ms}$; dIPSP alone, $18.4 \pm 5.5$ $\mathrm{ms} ; n=5$ ).

A similar reduction in latency and an improvement in the precision of APs after dEPSPs occurred when dEPSPs were preceded by dIPSPs (latency: dEPSP alone, $53.2 \pm 33.3 \mathrm{~ms} ; n=3$; dEPSP preceded by dIPSP, $32.0 \pm 22.9 \mathrm{~ms}$; SD of latency: dEPSP alone, $47.1 \pm 16.5 \mathrm{~ms}$; dEPSP preceded by dIPSP; $17.1 \pm 13.4 \mathrm{~ms}$; $n=3)$. Together, these data demonstrate that IPSPs can dynamically modulate the efficacy of excitatory synaptic integration according to their precise timing relative to EPSPs.

To provide additional evidence that the recovery of $\mathrm{Na}_{\mathrm{v}}$ channels from inactivation by an IPSP is important for the subsequent enhancement of excitatory synaptic integration, the experiment described in Figure $5 B$ was repeated under control conditions and after reducing the availability of $\mathrm{Na}_{\mathrm{v}}$ channels by $\sim 20 \%$ with 2 nM TTX (Fig. 6). Because the probability of neurotransmitter release is affected by TTX, the responses to synthetic synaptic conductances were studied. TTX at $2 \mathrm{nM}$ reduced the strength of dEPSP-AP coupling leading to a significant increase in the latency [WSR test; control, $15.2 \pm 8.7 \mathrm{~ms} ; 2 \mathrm{~nm}$ TTX, $30.1 \pm 17.8$ ms; $n=6 ; p=0.0313$ (Fig. $6 A i, A i i, B i$ )] and variability [SD of latency; control, $9.7 \pm 5.7 \mathrm{~ms} ; 2 \mathrm{nM} \mathrm{TTX}, 21.6 \pm 13.5 \mathrm{~ms} ; n=6$; $p=0.0313$ (Fig. 6Ai,Aii,Bii)] of dEPSP-driven APs compared with control conditions. Comparison of individual traces at various phases of the interspike interval (Fig. 6Ci-Ciii) further illustrate the reduced efficacy of dEPSPs after dIPSPs in the presence of 2 nM TTX. 


\section{Feedback inhibition facilitates the entrainment of APs by rhythmic excitatory synaptic inputs}

In the absence of movement, STN neurons receive tonic GABAergic inhibitory inputs from the GP (DeLong et al., 1985; Urbain et al., 2002). During movement, cortical-mediated excitation of STN neurons is rapidly curtailed by feedback inhibition from reciprocally connected GP neurons (Ryan and Clark, 1992; Ryan et al., 1992; Fujimoto and Kita, 1993; Maurice et al., 1998). Under these circumstances, GABAergic inhibition may act to reduce the efficacy and duration of excitatory inputs (Eccles, 1965). In contrast, if cortical inputs to STN neurons are rhythmic in nature (Goldberg et al., 2002, 2004, Brown, 2003; Dostrovsky and Bergman, 2004) so that they are intervened by IPSPs that arise via feedback inhibition from the GP, they could be facilitated by the mechanisms described above. To test this possibility, EPSPs were evoked for $1 \mathrm{~s}$ in spontaneously active STN neurons in the $\beta$-frequency range ( 14 or $18 \mathrm{~Hz}$ ) in either isolation (Fig. $7 A$ ) or the presence of synthetic feedback inhibition (Fig. 7B). Although the excitation protocol produced a significant increase in firing rate of $43.2 \pm$ 19.4\% (14 Hz protocol; control, $7.5 \pm 3.1$ $\mathrm{Hz}$; excitation protocol, $10.7 \pm 4.3 \mathrm{~Hz}$; $n=6 ; p<0.031)$ and $58.1 \pm 57.0 \%(18$ $\mathrm{Hz}$ protocol; control, $8.8 \pm 4.4 \mathrm{~Hz}$; excitation protocol, $12.5 \pm 4.1 \mathrm{~Hz} ; n=9 ; p<$ $0.0039)$, there was relatively weak coupling of EPSPs to APs (Fig. 7A,C,D). When "feedback" inhibition was added to the excitation protocol (Fig. $7 B$ ), there was no significant reduction in discharge frequency (14 Hz protocol: control, $7.5 \pm 3.1$ $\mathrm{Hz}$; excitation-inhibition protocol, $6.8 \pm$ $4.3 \mathrm{~Hz} ; n=6, p=0.687 ; 18 \mathrm{~Hz}$ protocol: control, $8.8 \pm 4.4 \mathrm{~Hz}$; excitation-inhibition protocol, $7.5 \pm 4.4 \mathrm{~Hz} ; n=9 ; p=$ $0.195)$. However, in contrast to the excitation protocol, there was a clear increase in the efficiency of EPSP-AP coupling. Phase locking of APs within each IPSP-EPSP cycle was relatively discernable on the overlays of multiple trials (Fig. $7 \mathrm{Bi}$ ), spike raster displays (Fig. 7Bii), and peristimulus time histograms (Fig. 7Biii). At matching membrane potentials, the APs generated after EPSPs occurred earlier in the presence of inhibition (Fig. 7C), which is consistent with a reduction of the latency and variability of AP generation in the presence of feedback inhibition (Fig. 7D). The peaks and valleys observed in the peristimulus time histogram (Fig. 7Biii) indicated that feedback IPSPs promoted the emergence of EPSP-driven synchronized activity in STN neurons. Because an improvement in EPSP-AP coupling could result from synaptic plasticity (for review, see Bi and Poo, 2001), the ability of evoked EPSPs to trigger APs was analyzed across trials, but no sign of activity-dependent plasticity was observed. Indeed, seven neurons. ${ }^{*} p<0.05$
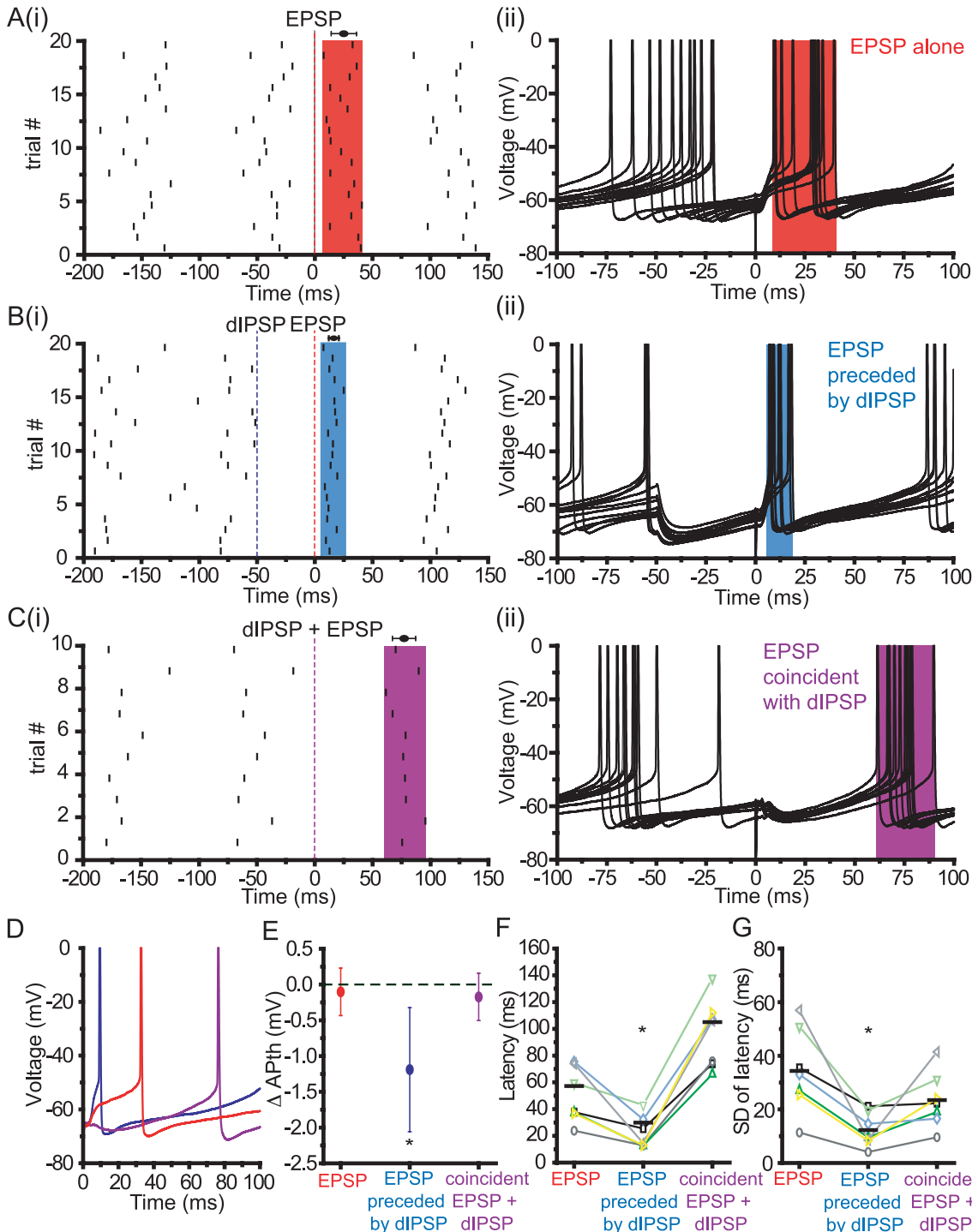

(ii)

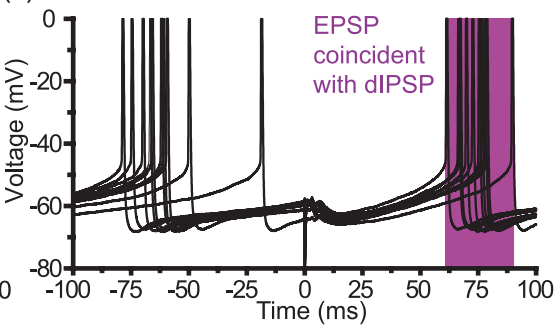

$F_{160} \quad G$

Figure 5. The coupling of APs to EPSPs is more efficient when EPSPs are preceded by but are not coincident with dIPSPs. $\boldsymbol{A}-\mathbf{G}$ Comparison of APs generated over multiple trials after EPSPs (20 trials; $\mathbf{A i}, \mathbf{A i i}, \mathbf{D}-\mathbf{G}$ ), EPSPs preceded by dIPSPs (20 trials; $\mathbf{B i}, \mathbf{B i i}$, D-G), and coincident EPSPs and dIPSPs (10 trials; $(\boldsymbol{C}, \mathbf{C i i}, \mathbf{D}-\mathbf{G})$ in a typical neuron; 0 ms represents the time at which the EPSP was ectrically stimulated. $\mathbf{A i}, \mathbf{B i}, \mathbf{C i}$, Rasters of AP activity over multiple trials of the three protocols. The time windows over which APs were generated after EPSPs are highlighted by colored rectangles. Aii, Bii, Cii, Ten examples of APs generated in response to EPSPs for each protocol. $D$, Comparison of EPSPs and subsequent APs evoked at identical voltages in the absence of a dIPSP (red), after a reduction in APth was also significantly greater than for EPSPs preceded by dIPSPs than for dIPSPs alone (compare with Fig. 3C). $\boldsymbol{F}$ $\mathbf{G}$, The latency $(\boldsymbol{F})$ and the variability ( $\mathbf{G}$; SD of latency) of AP generation after EPSPs were reduced when EPSPs were preceded by coincident with dIPSPs. Results for seven neurons (each neuron is represented by a distinct symbol and color) are represented graphically. Black horizontal bars represent the mean latency and mean SD of latency associated with each protocol in

similar results were obtained with trains of dEPSPs (Fig. 8), excluding plasticity of glutamatergic synaptic inputs as the causative mechanism. Because experiments with evoked and dEPSPs yielded similar results, the data obtained from stimulated and dEPSPs were pooled for each frequency. At $14 \mathrm{~Hz}$ (Fig. 7), the mean EPSP latency (excitation protocol, $25.4 \pm 6.4 \mathrm{~ms}$; excitation-inhibition protocol, $11.5 \pm 6.1 \mathrm{~ms} ; n=6 ; p=0.031)$ and precision of AP generation (excitation protocol, $19.9 \pm 3.6 \mathrm{~ms}$; excitation-inhibition protocol, $5.5 \pm 2.0 \mathrm{~ms} ; n=6 ; p=0.031$ ) were, respectively, reduced and enhanced when feedback inhibition was present. At $18 \mathrm{~Hz}$ (Fig. 8), the latency was also significantly reduced (excitation protocol, $18.7 \pm 5.0 \mathrm{~ms}$; excitation- 

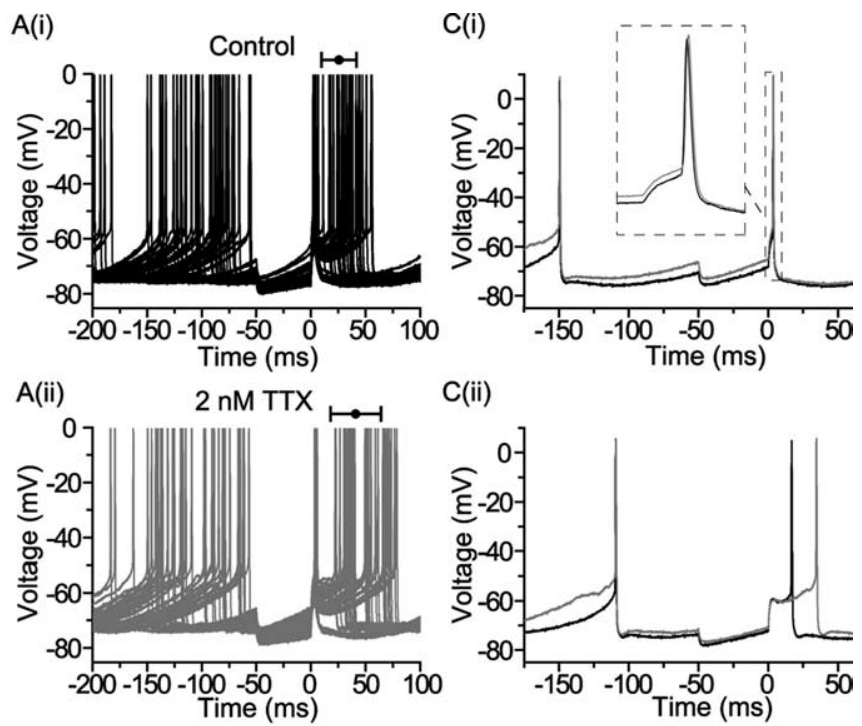

C(ii)
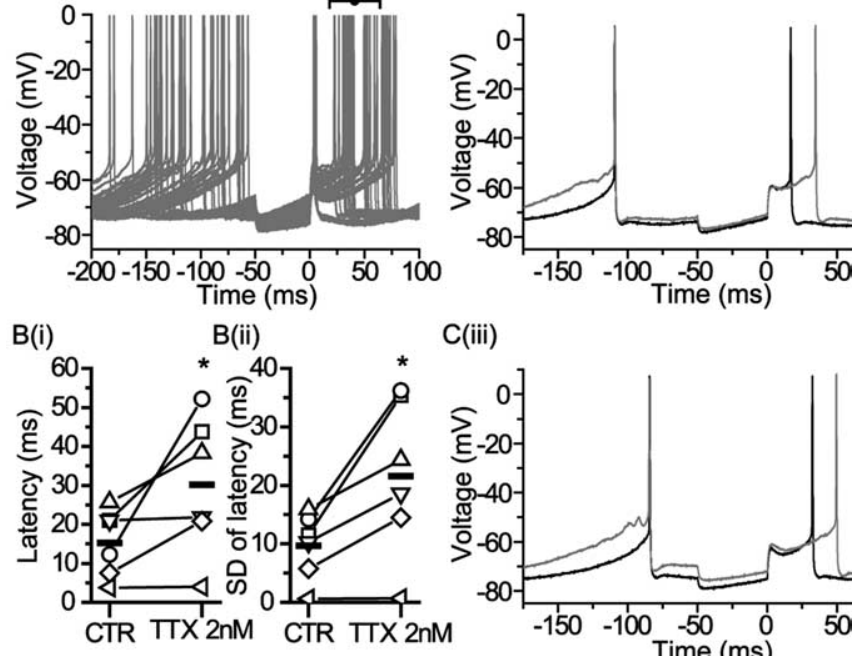

C(iii)

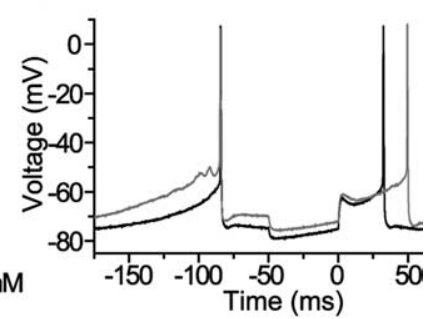

Figure 6. A, Comparison of APs generated over 50 trials after a dIPSP-dEPSP sequence in control conditions (Ai; black traces) and in $2 \mathrm{~nm} \mathrm{TTX,} \mathrm{which} \mathrm{reduced} \mathrm{the} \mathrm{availability} \mathrm{of} \mathrm{Na}_{\mathrm{v}}$ channels by $\sim 20 \%$ (Aii; gray traces); 0 ms represents the time at which the dEPSP was generated. $\boldsymbol{B}$, The latency $(\boldsymbol{B} \boldsymbol{i})$ and the variability (Bii; SD of latency) of AP generation after the dIPSP - dEPSP sequence were significantly increased in the presence of $2 \mathrm{~nm}$ TTX. Results for six neurons (each neuron is represented by a distinct symbol) are represented graphically. Black horizontal bars represent the mean latency and mean SD of latency associated with each experimental condition in six neurons. CTR, Control. Ci-Ciii, Examples of superimposed individual traces taken from the same neuron in control conditions (black traces) and in 2 nM TTX (gray traces) at various phases of the interspike interval. Note that the dEPSP-driven AP occurs earliest in control conditions, even when the membrane potential at which the dEPSP is injected is more hyperpolarized. ${ }^{*} p<0.05$.

inhibition protocol, $7.3 \pm 3.3 \mathrm{~ms} ; n=9 ; p<0.001)$ and the precision of AP generation was improved (excitation protocol, $15.6 \pm 4.1 \mathrm{~ms}$; excitation-inhibition protocol, $6.1 \pm 6.2 \mathrm{~ms} ; n=$ $9 ; p<0.001)$ in the presence of feedback inhibition.

\section{Discussion}

$\mathrm{Na}_{\mathrm{v}}$ channels are critical for autonomous oscillation and synaptic resetting

In the majority of autonomous oscillators, activity is driven by subthreshold $\mathrm{Na}^{+}$current (Raman and Bean, 1997; Bevan and Wilson, 1999; Taddese and Bean, 2002). Despite evidence that neurons possess a considerable reserve of $\mathrm{Na}_{\mathrm{v}}$ channels (Madeja, 2000), reductions in $\mathrm{Na}_{\mathrm{v}}$ channel availability during repetitive firing or pharmacological manipulation influence AP generation (Fleidervish et al., 1996; Colbert et al., 1997; Jung et al., 1997; Madeja, 2000; Colbert and Pan, 2002; Carr et al., 2003). In support of this principle, a $47 \%$ reduction in $\mathrm{Na}_{\mathrm{v}}$ channel availability in STN neurons with $5 \mathrm{nM}$ TTX did not abolish pacemaking but did reduce its frequency and depolarized APth.

After the complete blockade of $\mathrm{Na}_{\mathrm{v}}$ channels, subthreshold membrane potential oscillations were abolished and the voltage rested well below APth, which confirms that $\mathrm{Na}_{\mathrm{v}}$ channels are a
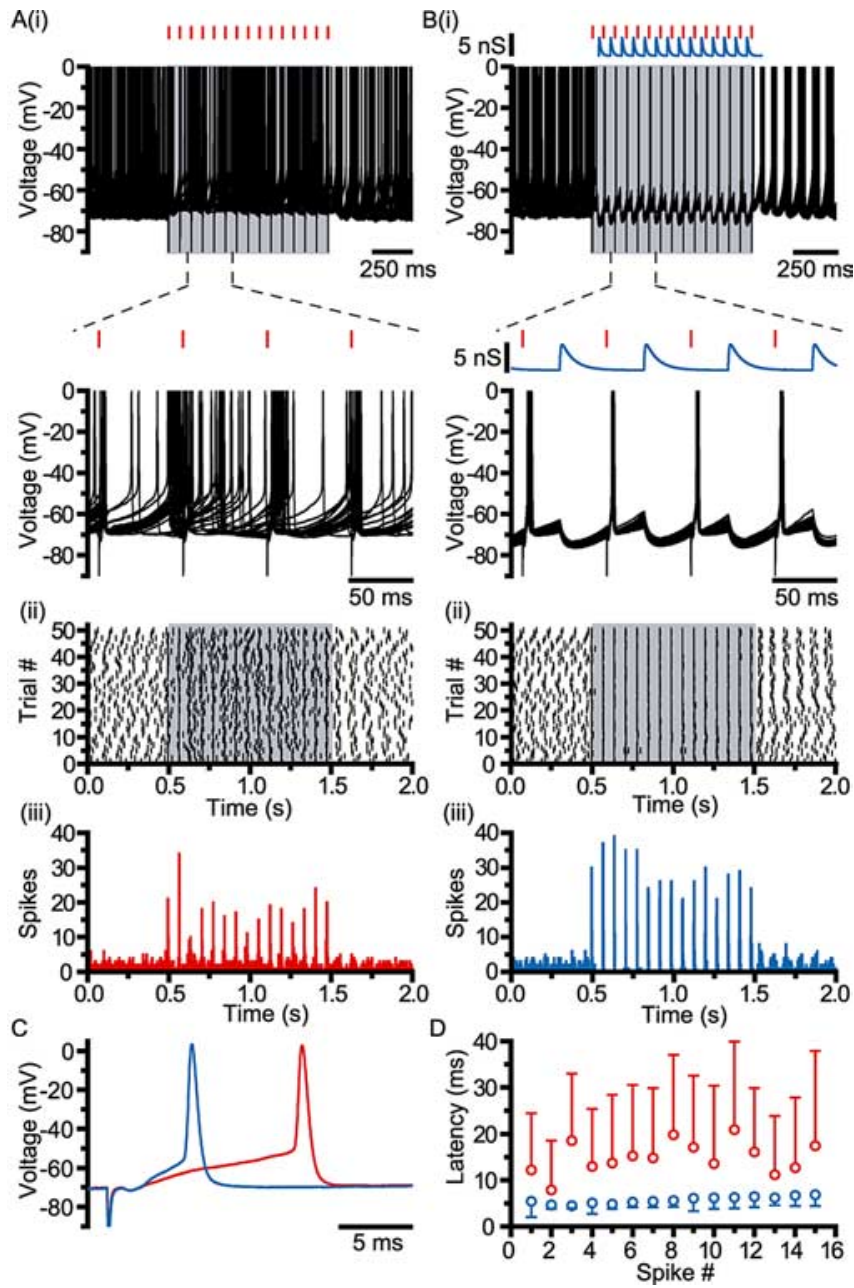

Figure 7. Feedback inhibition enhances the coupling of APs to rhythmic EPSPs. A, Trains of electrically stimulated EPSPs did not drive synchronized spiking in STN neurons. Ai, Top, Twenty superimposed trials during which a train of EPSPs was evoked at a frequency of $14 \mathrm{~Hz}$ (gray rectangle) for a period of $1 \mathrm{~s}$. EPSPs were stimulated at the times marked by the vertical bars above the graph. Bottom, Enlargement of EPSP-driven APs. Relatively weak phase-locked activity was observed in the peristimulus raster plot (Aii, highlighted gray box) and the peristimulus time histogram (Aiii) during the period of evoked EPSPs. B , Synthetic feedback inhibition enhanced EPSP-driven APs and promoted the emergence of phase-locked neuronal activity. $\boldsymbol{B i}$, Top, Overlay of 20 trials in which EPSPs and feedback dIPSPs were generated at a frequency of 14 $\mathrm{Hz}$. Each dIPSP was injected $20 \mathrm{~ms}$ after each evoked EPSP for $1 \mathrm{~s}$ (protocol illustrated above the graph). Bottom, Enlargement of excitation-inhibition sequences revealing the precise phase locking of EPSP-driven APs when feedback inhibition was incorporated. Aligned APs were more apparent on the peristimulus raster plots ( $B \mathbf{i i}$, gray box) and the peristimulus time histogram (Biii). C, Comparison of EPSPs and subsequent APs evoked at identical voltages in the absence (red) and presence (blue) of feedback inhibition. $\boldsymbol{D}$, The latency of AP generation was reduced and its precision (SD of latency) improved when dIPSPs intervened evoked EPSPs (blue) compared with the stimulation of EPSPs in isolation (red).

major mediator of depolarization at subthreshold voltages. The increased integral of dIPSPs after 100\% channel block and the increased latency and variability of the AP after a dIPSP after $20-50 \%$ channel block demonstrate that $\mathrm{Na}_{\mathrm{v}}$ channels actively terminate GABAergic IPSPs. The distinct roles of $\mathrm{Na}_{\mathrm{v}}$ channels in the integration of inhibitory inputs in STN and cortical neurons (Stuart, 1999) is presumably a reflection of the different biophysical properties of $\mathrm{Na}_{\mathrm{v}}$ and other channels in the two cell types.

The mean equilibrium potential of $\mathrm{GABA}_{\mathrm{A}}$ IPSPs has been determined previously to be $-79 \mathrm{mV}$ in STN neurons (Bevan et al., 2000, 2002a), although with junction potential correction, this value is closer to $-83 \mathrm{mV}$. This hyperpolarized value suggests 

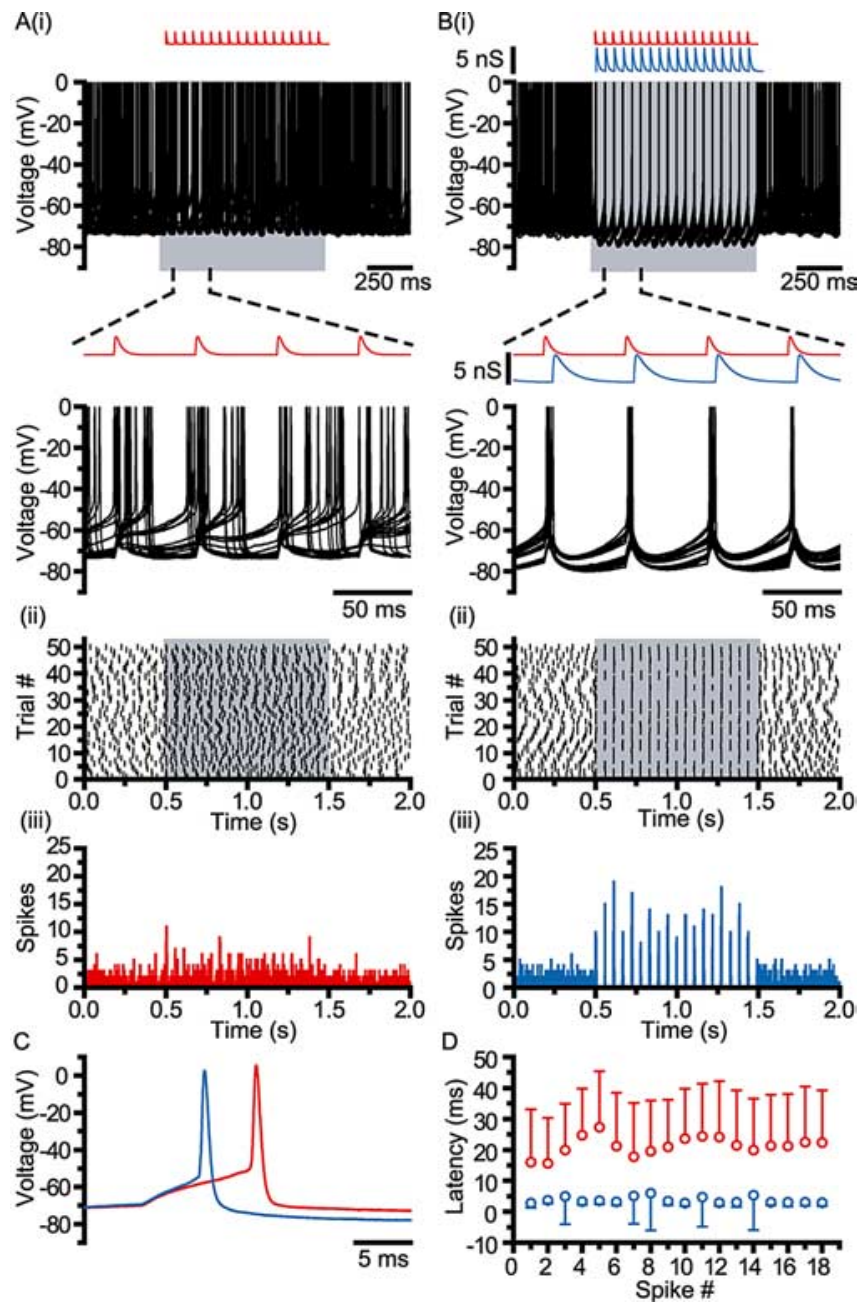

Figure 8. Feedback inhibition enhances the coupling of APs to rhythmic dEPSPS. Ai, Failure of an injected train of dEPSPs to drive phase-locked spiking in an STN neuron. Top, Twenty superimposed trials in which a train of dEPSPs was injected at a frequency of $18 \mathrm{~Hz}$ (gray rectangle) for a period of $1 \mathrm{~s}$. The pattern of dEPSP injection is shown above the graph. Bottom, Enlargement showing the imprecise timing of APs in response to rhythmic dEPSPs. The increase in stimulus-evoked neuronal activity on the peristimulus raster plot (Aii, highlighted gray box) and the peristimulus time histogram (Aiii) were not accompanied by correlated activity. $\boldsymbol{B}$, Feedback dIPSPs enhance the coupling dEPSPs and APs, leading to the emergence of synchronized neuronal activity. $\boldsymbol{B i}$, Top, 0 verlay of 20 trials in which dEPSPs and dIPSPs were generated at a frequency of $18 \mathrm{~Hz}$. Each dIPSP was injected $10 \mathrm{~ms}$ after the dEPSP, and this sequence was repeated for $1 \mathrm{~s}$ (protocol illustrated above the graph). Bi, Bottom, Enlargement of excitationinhibition sequences revealing the phase locking of APs to dEPSPs in the presence of feedback inhibition. Precisely driven APs were apparent from the peristimulus raster plot (Bii, gray box) and the peristimulus time histogram (Biii). C, Comparison of dEPSPs and subsequent APs evoked at identical voltages in the absence (red) and presence (blue) of feedback inhibition. $\boldsymbol{D}$, The latency of AP generation was reduced and its precision (SD of latency) was improved when feedback inhibition was incorporated (blue) compared with rhythmic excitation alone (red).

that $\mathrm{GABA}_{\mathrm{A}}$ IPSPs reset the phase of autonomous oscillation of STN neurons through the partial/complete deactivation of pacemaker $\mathrm{Na}_{\mathrm{v}}$ channels. Indeed, voltage-clamp experiments confirmed that IPSP waveforms reduced/eliminated subthreshold $\mathrm{Na}^{+}$current in STN neurons.

Although HCN channels operate in the range of potentials traversed by GABAergic IPSPs (Robinson and Siegelbaum, 2003), pharmacological blockade of these channels did not disrupt autonomous activity or resetting by single dIPSPs or stimulated IPSPs. Because HCN2 channels are the dominant $\mathrm{HCN}$ subunit in STN neurons, their nonparticipation is consistent with their relatively slow activation kinetics and hyperpolarized voltage dependence (Santoro et al., 2000; Robinson and Siegelbaum, 2003). In contrast, GP neurons express significant levels of HCN1, which endows their HCN channels with sufficiently rapid kinetics of activation and depolarized voltage dependence to participate in pacemaking and synaptic resetting (Chan et al., 2004). Moreover, because the majority of GP terminals innervate the proximal regions of STN neurons (Smith et al., 1990), most GP IPSPs are not in an appropriate position to activate the predominantly distal dendritic HCN channels (Magee, 1999; Lorincz et al., 2002; Williams and Stuart, 2003).

Nickel-sensitive $\mathrm{Ca}_{\mathrm{v}} 3$ channels do not participate in pacemaking or the response to single/low-frequency IPSPs. These channels underlie a low-threshold $\mathrm{Ca}^{2+}$ spike on which a rebound burst of APs rides in STN and other neurons (Nakanishi et al., 1987; Huguenard, 1996; Beurrier et al., 1999; Song et al., 2000; Hallworth et al., 2003). However, sufficient deinactivation of $\mathrm{Ca}_{\mathrm{v}} 3$ channels for the generation of a low-threshold $\mathrm{Ca}^{2+}$ spike requires barrages of summating IPSPs generated at frequencies greater than those studied here (Bevan et al., 2002a; Hallworth and Bevan, 2005).

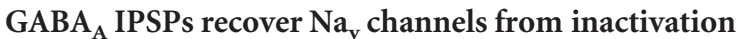

Using perforated patch recordings of STN neurons in slices as a voltage-clamp waveform, it was observed in isolated STN neurons that subthreshold and spike-associated $\mathrm{Na}^{+}$currents decline to a steady value. These data support the findings of Do and Bean (2003) that autonomous firing inactivates $\sim 40 \%$ of the total $\mathrm{Na}_{\mathrm{v}}$ channel population. Inactivation of $\mathrm{Na}_{\mathrm{v}}$ channels is mediated by distinct molecular mechanisms, which underlie socalled fast or slow inactivation. Among the properties that discriminate slow from fast inactivation (Hodgkin and Huxley, 1952; Rudy, 1978; Kuo and Bean, 1994; Martina and Jonas, 1997; Ellerkmann et al., 2001) are the kinetics of recovery from inactivation. For the slow inactivated state, recovery occurs with a time constant of several seconds, which is several orders of magnitude slower than the recovery from fast inactivation (Kuo and Bean, 1994; Ellerkmann et al., 2001; Carr et al., 2003; Do and Bean, 2003). After GABAergic IPSPs, APs were modified in a manner that suggested that there was a transient increase in $\mathrm{Na}_{\mathrm{v}}$ channel excitability. Indeed, voltage-clamp experiments confirmed that both subthreshold and spike-associated TTX-sensitive $\mathrm{Na}^{+}$currents were increased in a duration-dependent manner after inhibition. Thus, the data suggests that, during the autonomous activity of STN neurons, there is an accumulation of fastinactivation because a significant fraction of $\mathrm{Na}_{\mathrm{v}}$ channels can be recovered within the time course of a single inhibitory event.

The distribution of $\mathrm{Na}_{\mathrm{v}}$ channels deinactivated by IPSPs is unknown, but the ability of somatic dIPSPs to modify AP dynamics demonstrates that somatic inhibition is sufficient. Finally, the influence of inhibition on $\mathrm{Na}_{\mathrm{v}}$ channel availability must be a relatively robust action of inhibition in the STN because stimulated and dIPSPs were of similar magnitude to spontaneous IPSPs and therefore presumably represented the activity of a small number of afferent GP fibers.

\section{IPSPs enhance EPSP-AP coupling}

Traditionally, the GP is thought to restrain the activity of the STN and its excitatory drive to the output nuclei of the basal ganglia (Albin et al., 1989). However, the results provided in this study demonstrate that fast GABAergic inhibition can also prime STN neurons to respond more efficiently to excitatory input. The increased availability of $\mathrm{Na}_{\mathrm{v}}$ channels after an IPSP presumably 
contributes to the relative amplification of the EPSP (Figs. 5D, $7 C$ ), which, in concert with a reduction in APth accounts (at least in part) for the reduced latency of APs when they were preceded by a dIPSP (Fig. 8). In other cell types, $\mathrm{Na}_{\mathrm{v}}$ channels are also thought to amplify EPSPs (Stuart and Sakmann, 1995; Fricker and Miles, 2000; Gonzalez-Burgos and Barrionuevo, 2001). However, in most brain circuits, EPSP-IPSP sequences are more commonly observed than IPSP-EPSP sequences (Pouille and Scanziani, 2004). Indeed, this sequence also occurs when cortical excitation of STN neurons is relayed to the reciprocally connected GP, which in turn generates a feedback IPSP (Ryan and Clark, 1992; Maurice et al., 1998; Nambu et al., 2000; Kita et al., 2004). Because feedforward and/or feedback GABAergic inhibition are critical for the synchronization of neuronal network activity at a variety of functionally and pathologically relevant frequencies (Cobb et al., 1995; McCormick and Bal, 1997; McCormick, 1999; Beierlein et al., 2000; Tamas et al., 2000; Whittington et al., 2000; Klausberger et al., 2003; Pouille and Scanziani, 2004; Mann et al., 2005), the influence of feedback inhibition on the entrainment of STN neuronal activity neurons by rhythmic sequences of excitation was assessed. It was observed that the precision of spiking was greatly enhanced when rhythmic EPSPs were intervened by feedback IPSPs. Notably, the effect was not attributable solely to the restriction (by inhibition) of the time window in which APs could occur but also on the gain of intrinsic excitability described above, i.e., identical synthetic excitatory synaptic conductances injected at identical postsynaptic membrane potentials generated APs with reduced latency and variability when they were preceded by a dIPSP.

\section{Functional implications}

During normal and abnormal movement, rhythmic activity in the cerebral cortex and the basal ganglia are intimately related (Brown, 2003; Courtemanche et al., 2003; Berke et al., 2004; Goldberg et al., 2004). During normal movement the cortex, the STN-GP network and basal ganglia output nuclei exhibit coherent activity in the $\gamma$-frequency band $(30-100 \mathrm{~Hz})$, whereas in PD, which is characterized by akinesia, bradykinesia and limb tremor (4-8 Hz), coherent activity at lower frequencies is more commonly observed (Brown, 2003; Dostrovsky and Bergman, 2004). Rhythmic activity in the tremor frequency band may be generated within the dopamine-depleted STN-GP network (Plenz and Kitai, 1999; Bevan et al., 2002b; Hallworth and Bevan, 2005) through a mechanism similar to the one underlying spindle oscillations in the sensory thalamus (McCormick and Bal, 1997; McCormick, 1999). In addition, cortical $\beta$ oscillations may be transmitted abnormally to the extrastriatal basal ganglia via the corticosubthalamic pathway, leading to the pathological synchronization of spiking activity (Goldberg et al., 2002, 2004; Levy et al., 2002; Williams et al., 2002). Indeed, recent studies have established that the cerebral cortex can directly pattern pathological patterns of AP generation in the STN (Magill et al., 2001; Paz et al., 2005). But why should the STN be more sensitive to cortical idling rhythms in PD? Interestingly, the synaptic release of GABA and to a lesser extent glutamate are suppressed by the activation of presynaptic $\mathrm{D}_{2}$ dopamine receptors in the STN (Shen and Johnson, 2000; Cragg et al., 2004) and in experimental PD $\mathrm{GABA}_{\mathrm{A}}$ and AMPA receptor agonists generate larger currents in postsynaptic STN neurons (Shen and Johnson, 2005). Taking these observations together with the cellular mechanism described in this study, we propose that, in the dopamine-depleted STN, feedback inhibition is amplified, leading to the pathological expression of cortical $\beta$ oscillations in the STN and associated basal ganglia nuclei in PD.

\section{References}

Albin RL, Young AB, Penney JB (1989) The functional anatomy of basal ganglia disorders. Trends Neurosci 12:366-375.

Barry PH (1994) JPCalc: a software package for calculating liquid junction potential corrections in patch-clamp, intracellular, epithelial and bilayer measurements and for correcting junction potential measurements. J Neurosci Methods 51:107-116.

Beaumont V, Zucker RS (2000) Enhancement of synaptic transmission by cyclic AMP modulation of presynaptic Ih channels. Nat Neurosci 3:133-141.

Beierlein M, Gibson JR, Connors BW (2000) A network of electrically coupled interneurons drives synchronized inhibition in neocortex. Nat Neurosci 3:904-910.

Bergman H, Wichmann T, Karmon B, DeLong MR (1994) The primate subthalamic nucleus. II. Neuronal activity in the MPTP model of parkinsonism. J Neurophysiol 72:507-520.

Berke JD, Okatan M, Skurski J, Eichenbaum HB (2004) Oscillatory entrainment of striatal neurons in freely moving rats. Neuron 43:883-896.

Beurrier C, Congar P, Bioulac B, Hammond C (1999) Subthalamic nucleus neurons switch from single-spike activity to burst-firing mode. J Neurosci 19:599-609.

Beurrier C, Bioulac B, Hammond C (2000) Slowly inactivating sodium current $(\mathrm{I}(\mathrm{NaP}))$ underlies single-spike activity in rat subthalamic neurons. J Neurophysiol 83:1951-1957.

Bevan MD, Wilson CJ (1999) Mechanisms underlying spontaneous oscillation and rhythmic firing in rat subthalamic neurons. J Neurosci 19:7617-7628.

Bevan MD, Clarke NP, Bolam JP (1997) Synaptic integration of functionally diverse pallidal information in the entopeduncular nucleus and subthalamic nucleus in the rat. J Neurosci 17:308-324.

Bevan MD, Wilson CJ, Bolam JP, Magill PJ (2000) Equilibrium potential of GABA(A) current and implications for rebound burst firing in rat subthalamic neurons in vitro. J Neurophysiol 83:3169-3172.

Bevan MD, Magill PJ, Hallworth NE, Bolam JP, Wilson CJ (2002a) Regulation of the timing and pattern of action potential generation in rat subthalamic neurons in vitro by GABA-A IPSPs. J Neurophysiol $87: 1348-1362$.

Bevan MD, Magill PJ, Terman D, Bolam JP, Wilson CJ (2002b) Move to the rhythm: oscillations in the subthalamic nucleus-external globus pallidus network. Trends Neurosci 25:525-531.

Bi G, Poo M (2001) Synaptic modification by correlated activity: Hebb's postulate revisited. Annu Rev Neurosci 24:139-166.

Brown P (2003) Oscillatory nature of human basal ganglia activity: relationship to the pathophysiology of Parkinson's disease. Mov Disord 18:357-363.

Carr DB, Day M, Cantrell AR, Held J, Scheuer T, Catterall WA, Surmeier DJ (2003) Transmitter modulation of slow, activity-dependent alterations in sodium channel availability endows neurons with a novel form of cellular plasticity. Neuron 39:793-806.

Chan CS, Shigemoto R, Mercer JN, Surmeier DJ (2004) HCN2 and HCN1 channels govern the regularity of autonomous pacemaking and synaptic resetting in globus pallidus neurons. J Neurosci 24:9921-9932.

Chemin J, Monteil A, Perez-Reyes E, Bourinet E, Nargeot J, Lory P (2002) Specific contribution of human T-type calcium channel isotypes (alpha(1G), alpha(1H) and alpha(1I)) to neuronal excitability. J Physiol (Lond) 540:3-14.

Chevaleyre V, Castillo PE (2002) Assessing the role of Ih channels in synaptic transmission and mossy fiber LTP. Proc Natl Acad Sci USA 99:9538-9543.

Cobb SR, Buhl EH, Halasy K, Paulsen O, Somogyi P (1995) Synchronization of neuronal activity in hippocampus by individual GABAergic interneurons. Nature 378:75-78.

Colbert CM, Pan E (2002) Ion channel properties underlying axonal action potential initiation in pyramidal neurons. Nat Neurosci 5:533-538.

Colbert CM, Magee JC, Hoffman DA, Johnston D (1997) Slow recovery from inactivation of $\mathrm{Na}^{+}$channels underlies the activity-dependent attenuation of dendritic action potentials in hippocampal CA1 pyramidal neurons. J Neurosci 17:6512-6521. 
Connors BW (1984) Initiation of synchronized neuronal bursting in neocortex. Nature 310:685-687.

Courtemanche R, Fujii N, Graybiel AM (2003) Synchronous, focally modulated $\beta$-band oscillations characterize local field potential activity in the striatum of awake behaving monkeys. J Neurosci 23:11741-11752.

Cragg SJ, Baufreton J, Xue Y, Bolam JP, Bevan MD (2004) Synaptic release of dopamine in the subthalamic nucleus. Eur J Neurosci 20:1788-1802.

DeLong MR, Crutcher MD, Georgopoulos AP (1985) Primate globus pallidus and subthalamic nucleus: functional organization. J Neurophysiol 53:530-543.

Do MT, Bean BP (2003) Subthreshold sodium currents and pacemaking of subthalamic neurons: modulation by slow inactivation. Neuron 39:109-120.

Dodt HU, D’Arcangelo G, Zieglgansberger (1999) Infrared videomicroscopy. In: Imaging neurons. A laboratory manual (Yuste R, Lanni F, Konnerth A, eds), pp 7.1-7.8. New York: Cold Spring Harbor Laboratory.

Dostrovsky J, Bergman H (2004) Oscillatory activity in the basal gangliarelationship to normal physiology and pathophysiology. Brain 127:721-722.

Eccles JC (1965) Inhibition in thalamic and cortical neurones and its role in phasing neuronal discharges. Epilepsia 13:89-115.

Ellerkmann RK, Riazanski V, Elger CE, Urban BW, Beck H (2001) Slow recovery from inactivation regulates the availability of voltage-dependent $\mathrm{Na}^{+}$channels in hippocampal granule cells, hilar neurons and basket cells. J Physiol (Lond) 532:385-397.

Fleidervish IA, Friedman A, Gutnick MJ (1996) Slow inactivation of $\mathrm{Na}^{+}$ current and slow cumulative spike adaptation in mouse and guinea-pig neocortical neurones in slices. J Physiol (Lond) 493:83-97.

Fricker D, Miles R (2000) EPSP amplification and the precision of spike timing in hippocampal neurons. Neuron 28:559-569.

Fujimoto K, Kita H (1993) Response characteristics of subthalamic neurons to the stimulation of the sensorimotor cortex in the rat. Brain Res 609:185-192.

Goldberg JA, Boraud T, Maraton S, Haber SN, Vaadia E, Bergman H (2002) Enhanced synchrony among primary motor cortex neurons in the 1-methyl-4-phenyl-1,2,3,6-tetrahydropyridine primate model of Parkinson's disease. J Neurosci 22:4639-4653.

Goldberg JA, Rokni U, Boraud T, Vaadia E, Bergman H (2004) Spike synchronization in the cortex/basal-ganglia networks of Parkinsonian primates reflects global dynamics of the local field potentials. J Neurosci 24:6003-6010.

Gonzalez-Burgos G, Barrionuevo G (2001) Voltage-gated sodium channels shape subthreshold EPSPs in layer 5 pyramidal neurons from rat prefrontal cortex. J Neurophysiol 86:1671-1684.

Hallworth NE, Bevan MD (2005) Globus pallidus neurons dynamically regulate the activity pattern of subthalamic nucleus neurons through the frequency-dependent activation of postsynaptic $\mathrm{GABA}_{\mathrm{A}}$ and $\mathrm{GABA}_{\mathrm{B}}$ receptors. J Neurosci 25:6304-6315.

Hallworth NE, Wilson CJ, Bevan MD (2003) Apamin-sensitive small conductance calcium-activated potassium channels, through their selective coupling to voltage-gated calcium channels, are critical determinants of the precision, pace, and pattern of action potential generation in rat subthalamic nucleus neurons in vitro. J Neurosci 23:7525-7542.

Hodgkin AL, Huxley AF (1952) A quantitative description of membrane current and its application to conduction and excitation in nerve. J Physiol (Lond) 117:500-544.

Huguenard JR (1996) Low-threshold calcium currents in central nervous system neurons. Annu Rev Physiol 58:329-348.

Jung HY, Mickus T, Spruston N (1997) Prolonged sodium channel inactivation contributes to dendritic action potential attenuation in hippocampal pyramidal neurons. J Neurosci 17:6639-6646.

Kita H, Nambu A, Kaneda K, Tachibana Y, Takada M (2004) Role of ionotropic glutamatergic and GABAergic inputs on the firing activity of neurons in the external pallidum in awake monkeys. J Neurophysiol 92:3069-3084.

Klausberger T, Magill PJ, Marton LF, Roberts JD, Cobden PM, Buzsaki G, Somogyi P (2003) Brain-state- and cell-type-specific firing of hippocampal interneurons in vivo. Nature 421:844-848.

Kuo CC, Bean BP (1994) $\mathrm{Na}^{+}$channels must deactivate to recover from inactivation. Neuron 12:819-829.

Kuo CC, Yang S (2001) Recovery from inactivation of t-type $\mathrm{Ca}^{2+}$ channels in rat thalamic neurons. J Neurosci 21:1884-1892.
Kyrozis A, Reichling DB (1995) Perforated-patch recording with gramicidin avoids artifactual changes in intracellular chloride concentration. J Neurosci Methods 57:27-35.

Levy R, Hutchison WD, Lozano AM, Dostrovsky JO (2002) Synchronized neuronal discharge in the basal ganglia of parkinsonian patients is limited to oscillatory activity. J Neurosci 22:2855-2861.

Lorincz A, Notomi T, Tamas G, Shigemoto R, Nusser Z (2002) Polarized and compartment-dependent distribution of HCN1 in pyramidal cell dendrites. Nat Neurosci 5:1185-1193.

Ludwig A, Zong X, Stieber J, Hullin R, Hofmann F, Biel M (1999) Two pacemaker channels from human heart with profoundly different activation kinetics. EMBO 18:2323-2329.

Madeja M (2000) Do neurons have a reserve of sodium channels for the generation of action potentials? A study on acutely isolated CA1 neurons from the guinea-pig hippocampus. Eur J Neurosci 12:1-7.

Magee JC (1999) Dendritic lh normalizes temporal summation in hippocampal CA1 neurons. Nat Neurosci 2:508-514.

Magill PJ, Bolam JP, Bevan MD (2001) Dopamine regulates the impact of the cerebral cortex on the subthalamic nucleus-globus pallidus network. Neuroscience 106:313-330.

Mainen ZF, Sejnowski TJ (1995) Reliability of spike timing in neocortical neurons. Science 268:1503-1506.

Mann EO, Suckling JM, Hajos N, Greenfield SA, Paulsen O (2005) Perisomatic feedback inhibition underlies cholinergically induced fast network oscillations in the rat hippocampus in vitro. Neuron 45:105-117.

Martina M, Jonas P (1997) Functional differences in $\mathrm{Na}^{+}$channel gating between fast-spiking interneurones and principal neurones of rat hippocampus. J Physiol (Lond) 505:593-603.

Maurice N, Deniau JM, Glowinski J, Thierry AM (1998) Relationships between the prefrontal cortex and the basal ganglia in the rat: physiology of the corticosubthalamic circuits. J Neurosci 18:9539-9546.

McCormick DA (1999) Are thalamocortical rhythms the Rosetta Stone of a subset of neurological disorders? Nat Med 5:1349-1351.

McCormick DA, Bal T (1997) Sleep and arousal: thalamocortical mechanisms. Annu Rev Neurosci 20:185-215.

Monteggia LM, Eisch AJ, Tang MD, Kaczmarek LK, Nestler EJ (2000) Cloning and localization of the hyperpolarization-activated cyclic nucleotidegated channel family in rat brain. Brain Res Mol Brain Res 81:129-139.

Nakanishi H, Kita H, Kitai ST (1987) Electrical membrane properties of rat subthalamic neurons in an in vitro slice preparation. Brain Res 437:35-44.

Nambu A, Tokuno H, Hamada I, Kita H, Imanishi M, Akazawa T, Ikeuchi Y, Hasegawa N (2000) Excitatory cortical inputs to pallidal neurons via the subthalamic nucleus in the monkey. J Neurophysiol 84:289-300.

Neher E (1992) Correction for liquid junction potentials in patch clamp experiments. Methods Enzymol 207:123-131.

Overton PG, Greenfield SA (1995) Determinants of neuronal firing pattern in the guinea-pig subthalamic nucleus: an in vivo and in vitro comparison. J Neural Transm Park Dis Dement Sect 10:41-54.

Paz JT, Deniau JM, Charpier S (2005) Rhythmic bursting in the corticosubthalamo-pallidal network during spontaneous genetically determined spike and wave discharges. J Neurosci 25:2092-2101.

Plenz D, Kitai ST (1999) A basal ganglia pacemaker formed by the subthalamic nucleus and external globus pallidus. Nature 400:677-682.

Pouille F, Scanziani M (2004) Routing of spike series by dynamic circuits in the hippocampus. Nature 429:717-723.

Raman IM, Bean BP (1997) Resurgent sodium current and action potential formation in dissociated cerebellar Purkinje neurons. J Neurosci 17:4517-4526.

Robinson HP, Kawai N (1993) Injection of digitally synthesized synaptic conductance transients to measure the integrative properties of neurons. J Neurosci Methods 49:157-165.

Robinson RB, Siegelbaum SA (2003) Hyperpolarization-activated cation currents: from molecules to physiological function. Annu Rev Physiol 65:453-480.

Rudy B (1978) Slow inactivation of the sodium conductance in squid giant axons. Pronase resistance. J Physiol (Lond) 283:1-21.

Ryan LJ, Clark KB (1992) Alteration of neuronal responses in the subthalamic nucleus following globus pallidus and neostriatal lesions in rats. Brain Res Bull 29:319-327.

Ryan LJ, Sanders DJ, Clark KB (1992) Auto- and cross-correlation analysis of subthalamic nucleus neuronal activity in neostriatal- and globus pallidal-lesioned rats. Brain Res 583:253-261. 
Santoro B, Chen S, Luthi A, Pavlidis P, Shumyatsky GP, Tibbs GR, Siegelbaum SA (2000) Molecular and functional heterogeneity of hyperpolarization-activated pacemaker channels in the mouse CNS. J Neurosci 20:5264-5275.

Shen KZ, Johnson SW (2000) Presynaptic dopamine D2 and muscarine M3 receptors inhibit excitatory and inhibitory transmission to rat subthalamic neurones in vitro. J Physiol (Lond) 525:331-341.

Shen KZ, Johnson SW (2005) Dopamine depletion alters responses to glutamate and GABA in the rat subthalamic nucleus. NeuroReport 16:171-174.

Smith MR, Nelson AB, Du Lac S (2002) Regulation of firing response gain by calcium-dependent mechanisms in vestibular nucleus neurons. J Neurophysiol 87:2031-2042.

Smith Y, Bolam JP, Von Krosigk M (1990) Topographical and synaptic organization of the GABA-containing pallidosubthalamic projection in the rat. Eur J Neurosci 2:500-511.

Smith Y, Bevan MD, Shink E, Bolam JP (1998) Microcircuitry of the direct and indirect pathways of the basal ganglia. Neuroscience 86:353-387.

Song WJ, Baba Y, Otsuka T, Murakami F (2000) Characterization of $\mathrm{Ca}^{2+}$ channels in rat subthalamic nucleus neurons. J Neurophysiol $84: 2630-2637$.

Stuart G (1999) Voltage-activated sodium channels amplify inhibition in neocortical pyramidal neurons. Nat Neurosci 2:144-150.

Stuart G, Sakmann B (1995) Amplification of EPSPs by axosomatic sodium channels in neocortical pyramidal neurons. Neuron 15:1065-1076.

Taddese A, Bean BP (2002) Subthreshold sodium current from rapidly inactivating sodium channels drives spontaneous firing of tuberomammillary neurons. Neuron 33:587-600.
Tamas G, Buhl EH, Lorincz A, Somogyi P (2000) Proximally targeted GABAergic synapses and gap junctions synchronize cortical interneurons. Nat Neurosci 3:366-371.

Urbain N, Rentero N, Gervasoni D, Renaud B, Chouvet G (2002) The switch of subthalamic neurons from an irregular to a bursting pattern does not solely depend on their GABAergic inputs in the anesthetic-free rat. J Neurosci 22:8665-8675.

Wehr M, Zador AM (2003) Balanced inhibition underlies tuning and sharpens spike timing in auditory cortex. Nature 426:442-446.

Whittington MA, Traub RD, Kopell N, Ermentrout B, Buhl EH (2000) Inhibition-based rhythms: experimental and mathematical observations on network dynamics. Int J Psychophysiol 38:315-336.

Wichmann T, Bergman H, DeLong MR (1994) The primate subthalamic nucleus. I. Functional properties in intact animals. J Neurophysiol 72:494-506.

Williams D, Tijssen M, Van Bruggen G, Bosch A, Insola A, Di Lazzaro V, Mazzone P, Oliviero A, Quartarone A, Speelman H, Brown P (2002) Dopamine-dependent changes in the functional connectivity between basal ganglia and cerebral cortex in humans. Brain 125:1558-1569.

Williams SR, Stuart GJ (2003) Voltage- and site-dependent control of the somatic impact of dendritic IPSPs. J Neurosci 23:7358-7367.

Williams SR, Toth TI, Turner JP, Hughes SW, Crunelli V (1997) The "window" component of the low threshold $\mathrm{Ca}^{2+}$ current produces input signal amplification and bistability in cat and rat thalamocortical neurones. J Physiol (Lond) 505:689-705.

Wolfart J, Roeper J (2002) Selective coupling of T-type calcium channels to SK potassium channels prevents intrinsic bursting in dopaminergic midbrain neurons. J Neurosci 22:3404-3413. 